\title{
Carbon-carbon cross-coupling reactions of organomagnesium reagents with a variety of electrophilic substrates mediated by iron catalysts
}

\author{
Adnan A. Dahadha $\odot^{*}$, Mohammad M. Aldhoun $\oplus^{2}$, Mohammed Hassan $\odot^{3,4}$, \\ Qutaiba A. Ibrahim $\odot$ and Nesrin T. Talat ${ }^{5}$ \\ ${ }^{1}$ Biotechnology Department, Faculty of Science, Philadelphia University, Amman, Jordan \\ ${ }^{2}$ Faculty of Pharmacy, Philadelphia University, Amman, Jordan \\ ${ }^{3}$ Basic Sciences and Mathematics Department, Faculty of Science, Philadelphia University, Amman, \\ Jordan \\ ${ }^{4}$ Chemistry Department, Faculty of Science, Ibb University, Ibb, Yemen \\ ${ }^{5}$ Mechanical Department, Faculty of Engeneering, Al-Balqa Applied University, Irbid, Jordan
}

(Received December 20, 2020; Revised January 22, 2021; Accepted January 24, 2021)

\begin{abstract}
Iron complexes are one of the most promising catalysts for carbon-carbon coupling reactions due to their relatively low cost, widespread availability as well as lower toxicity. Many researches have been successfully done to develop efficient protocols for the cross-coupling reactions of organomagnesium reagents with various substrates mediated by iron catalysts to generate a wide spectrum of important organic compounds. This review covers significant developments in iron catalyzed cross-coupling reactions over the past ten years.
\end{abstract}

Keywords: Iron catalysts; organomagnesium reagents; carbon-carbon formation; cross-coupling reactions. @2021 ACG Publication. All right reserved.

\section{Introduction}

Transition metal catalyzed cross-coupling reactions are widely used for the construction of carbon-carbon bonds, enabling the synthesis of versatile and significant organic compounds ${ }^{1-6}$. In 1971, Kochi et al. reported the first iron catalyzed cross-coupling reaction of vinyl bromides with alkylmagnesium reagents ${ }^{7-10}$. Later, in 1972, Kumada, Tamao and Corriu independently reported an excellent method for the formation of carbon-carbon bonds by nickel catalyzed cross-coupling reactions of a broad spectrum of organomagnesium reagents and organohalide substrates, while palladium catalyzed Kumada coupling was first demonstrated by Murahashi in $1975^{11-14}$. However, iron being less expensive than palladium and nickel, in addition to its lower toxicity, makes it an appropriate catalyst for the metal catalyzed cross-coupling reactions ${ }^{15-22}$. Indeed, iron catalysts have led to the dramatic development of new cross-coupling reactions, as will be discussed herein ${ }^{23-25}$.

\footnotetext{
*Corresponding author: E-Mail: Adnan.dahadha_chem@yahoo.com, adahadha@philadephia.edu.jo, Phone: + 962792113020; Fax: + 96264799040 .
} 
Most of organomagnesium reagents are prepared by the reaction of an organic halide with magnesium in ethereal solution under an inert atmosphere. During the past century, the organomagnesium reagents have been the most broadly employed as organometallic reagents ${ }^{26-29}$. In general, organomagnesium reagents remain desirable coupling partners owing to the ease of their preparation and many of them are commercially available ${ }^{30-32}$.

\section{General Mechanism of Iron Catalyzed Cross Coupling Reaction of Organomagnesium Reagents with Substrates}

Numerous mechanistic studies targeting the iron-catalyzed coupling between various substrates and organomagnesium reagents have been published by several groups. In general, the metal catalyzed coupling reaction is believed to consist of three major steps: oxidative addition, transmetalation, and reductive elimination. Whereas, the catalytic cycle of iron catalyzed cross coupling starts with the formation of low-valent iron cluster species $\left[\mathrm{Fe}(\mathrm{MgX})_{2}\right]$ via the reaction of iron salts with $\mathrm{EtMgBr}$ and higher homologues (A). Oxidative addition of the carbon-halogen bond to the bimetallic clusters to construct an organoiron halide (B) is followed by subsequent reaction with $\mathrm{RMgX}$ to generate diorganoiron intermediates $(\mathbf{C})$. Finally, reductive elimination affords the corresponding coupled product and regenerate the catalytically active species (D) (Scheme 1) ${ }^{33-35}$. Although this mechanism is widely accepted, as it is speculative, it requires a considerable amount of further work to prove its veracity.
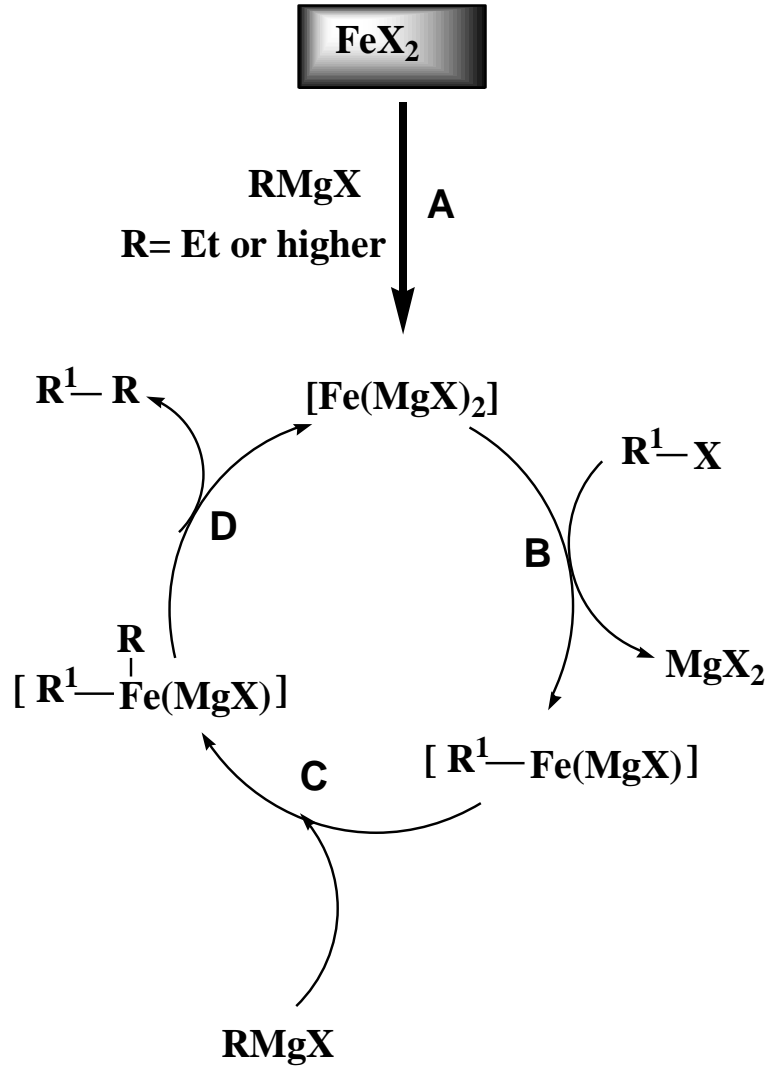

Scheme 1. The general mechanism of iron catalyzed cross-coupling organomagnesium with substrates

\section{Iron Catalyzed Cross-coupling of Organomagnesium Reagents}

Iron-catalyzed cross-coupling reactions of various organomagnesium halides with organic substrates have emerged as an extremely efficient synthetic tool, and the development has reached a level of the preparation of unique and versatile organic molecules by virtue of the diversity of organomagnesium halides and wide range of functional groups, which can be incorporated into these 
reagents. This review highlights cross-coupling reactions according to the types of organic moieties combined with organomagnesium reagents with catalysis based on iron complexes.

\subsection{Iron Catalyzed Cross-coupling of Alkylmagnesium Reagents}

$\mathrm{Csp}^{2}-\mathrm{Csp}^{3}$ bonds are usually observed in chemical structures of natural products, pharmaceuticals, agrochemicals and ligands for catalysis. In 2012, Neil K. Garg et al. for the first time described a novel protocol for $\mathrm{FeCl}_{2}$ mediated coupling of aryl or heterocyclic sulfamates $\mathbf{1 a}$ and carbamates $\mathbf{1 b}$ with hexylmagnesium chloride $\mathbf{2}$ in the presence of $\mathrm{N}$-heterocyclic carbene ligands like 1,3-bis(2,4,6-trimethylphenyl)-4,5-dihydroimidazol-1-ium chloride (SlMes $\cdot \mathrm{HCl})$ to generate the desired $\mathrm{Csp}^{2}-\mathrm{Csp}^{3}$ bonds in acceptable yields $\mathbf{4 a}, \mathbf{4 b}, \mathbf{5 a}, \mathbf{5 b}, \mathbf{6 a}$ and $\mathbf{6 b}$ (Scheme 2$)^{36}$. N-Heterocyclic carbenes (NHC) represent a versatile kind of ancillary ligands due to their tunable steric and electronic properties that might provide a necessary stabilizing effect in organometallic systems during the coupling reaction. Regardless, electron deficient and rich sulfamate and carbamate substrates have efficiently undergone cross-coupling with hexylmagnesium chloride furnishing relatively good yields of alkylated products $7 \mathbf{a}$, $\mathbf{7 b}, \mathbf{8 a}, \mathbf{8 b}, 9 \mathbf{a}$ and $\mathbf{9 b}$. In this optimized cross-coupling methodology, several heterocyclic substrates such as indole and dihydrobenzofuran have also been successfully coupled with alkylmagnesium reagents. However, there is a need to develop this coupling protocol to operate under milder conditions without further solvents.

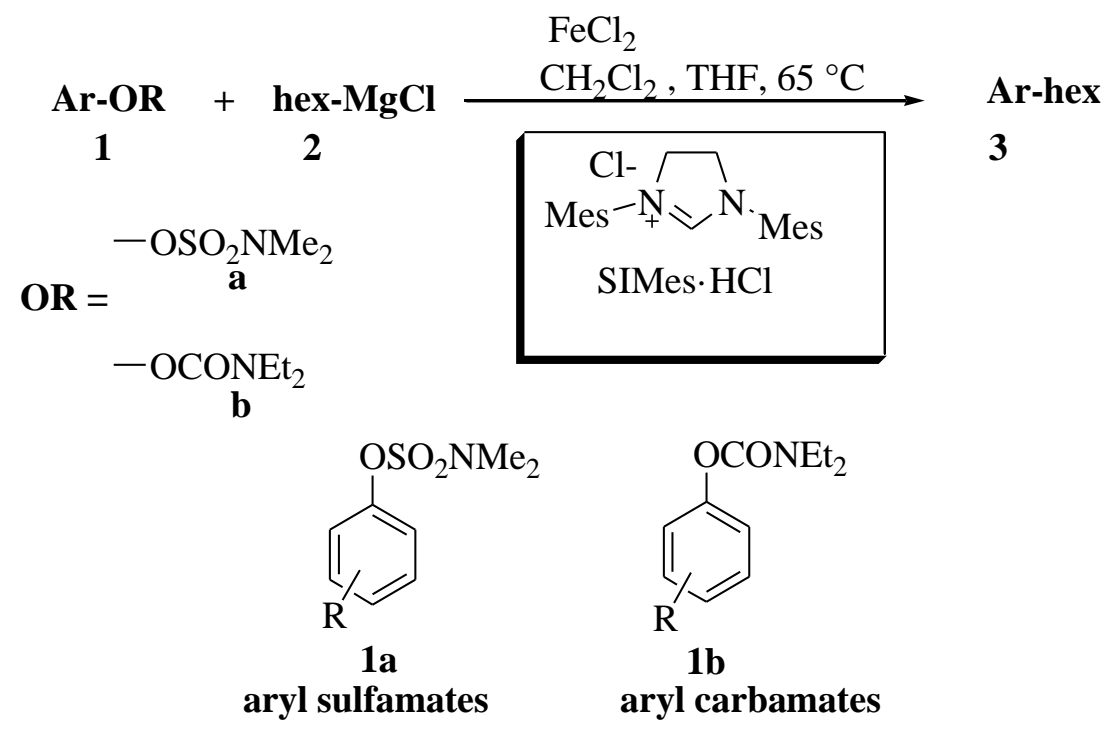

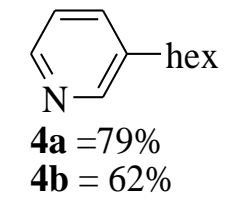

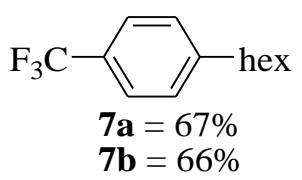

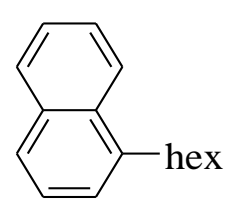

$$
\mathbf{5 a}=84 \%
$$$$
\mathbf{5 b}=78 \%
$$

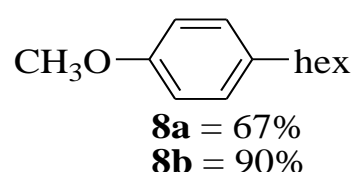

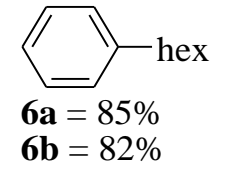

$\mathbf{6 b}=82 \%$

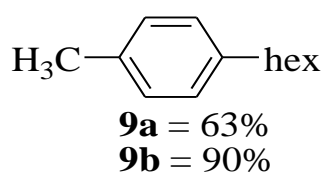

Scheme 2. Coupling reaction of aryl carbamates and sulfamates with n-hexylmagnesium chloride using iron catalyst

The scope of iron-catalyzed cross-coupling reactions has been considerably expanded by involving a variety of organomagnesium compounds and electrophilic substrates. Corannulene is a polycyclic aromatic hydrocarbon, consisting of a cyclopentane ring fused with five benzene rings. Corannulene derivatives have a significant role in the arena of organic electronics and supramolecular architectures ${ }^{[37]}$ Jay S. Siegel and his colleagues demonstrated an efficient method for coupling of sympentachlorocorannulene substrate $\mathbf{1 0}$ and various alkylmagnesium bromides $(\mathrm{RMgBr})$ at room temperature within $2.5 \mathrm{~h}$ using $0.25 \mathrm{~mol} \%$ of $\mathrm{Fe}(\mathrm{acac})_{3}$ in THF-NMP solution to produce applicable 
corannulene derivatives with a broad spectrum of functional groups in moderate to good yields (Scheme 3 , 11a-11d $)^{38}$. Noteworthy, the coupled products showed good solubility in common organic solvents (THF, DCM, MeOH), and therefore it can be derivatized easily to enhance its electron affinity.

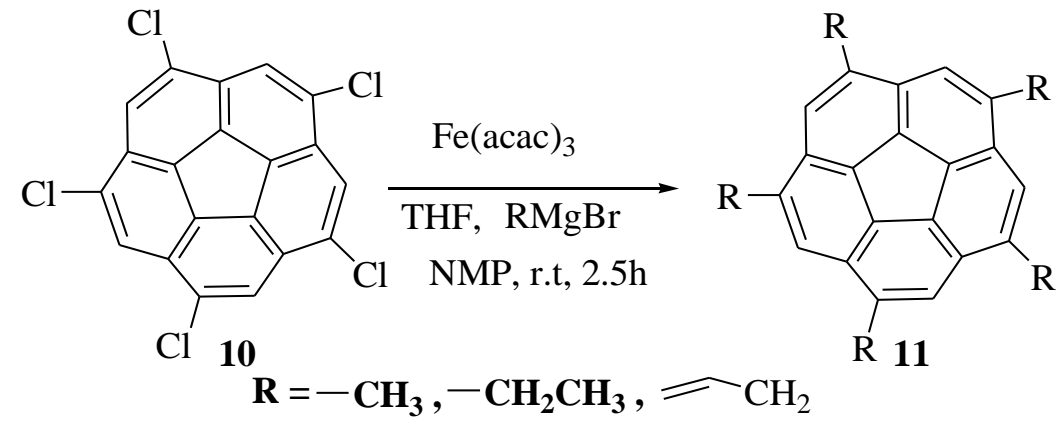<smiles>Cc1cc2c(C)cc3c(C)cc4c(C)cc5c(C)cc1c1c5c4c3c21</smiles><smiles>CCc1cc2c(CC)cc3c(CC)cc4c(CC)cc5c(CC)cc1c1c5c4c3c21</smiles><smiles>C=CCc1cc2c(CC=C)cc3c(CC=C)cc4c(CC=C)cc5c(CC=C)cc1c1c5c4c3c21</smiles>

Scheme 3. Fe(acac) $)_{3}$ catalyzed cross-coupling of $\mathbf{1 0}$ with various alkylmagnesium bromides

In 2012, Perry and coworkers achieved some successful coupling reactions of primary and secondary alkylmagnesium chlorides $\mathbf{1 3}$ with non-activated, electron rich aryl chloride substrates $\mathbf{1 2}^{39}$. Using $\mathrm{FeCl}_{2 *}\left(\mathrm{H}_{2} \mathrm{O}\right)_{4}$ as a superior catalyst precursor in combination with a bulky 1,3-bis(2,6diisopropylphenyl)imidazol-2-ylidene as an effective preligand has proved to be powerful catalyst system in the coupling reaction. Normally, the use of primary and secondary alkylmagnesium reagents as nucleophiles in cross-couplings often produces low yields of the desired products due to competitive $\beta$ hydrogen elimination and reinsertion prior to reductive elimination. This issue was addressed via employing two various cross-coupling protocols. In method A, all of the alkylmagnesium chloride was completely added at the beginning of the reaction, while in method B half of the alkylmagnesium chloride was added to aryl chloride substrates initially and the remaining second half was added after one hour. Nevertheless, the use of alkylmagnesium reagents as nucleophiles in cross-couplings produced desired product in excellent yields, in addition to the formation of byproduct isomers in low yields (Table 1, entries, 1-5). When coupling reaction of cyclohexylmagnesium bromide with substituted aryl chlorides was performed, moderate cross coupling yields were obtained (entries, 6-9). Undesired n-alkyl isomers were produced in this coupling reaction, including secondary alkylmagnesium reagents, due to occurring the reversible $\beta$-hydrogen elimination in competition with the desired reductive elimination.

Table 1. Iron-catalyzed cross-coupling of primary and secondary alkylmagnesium chloride reagents with non-activated aryl chlorides 


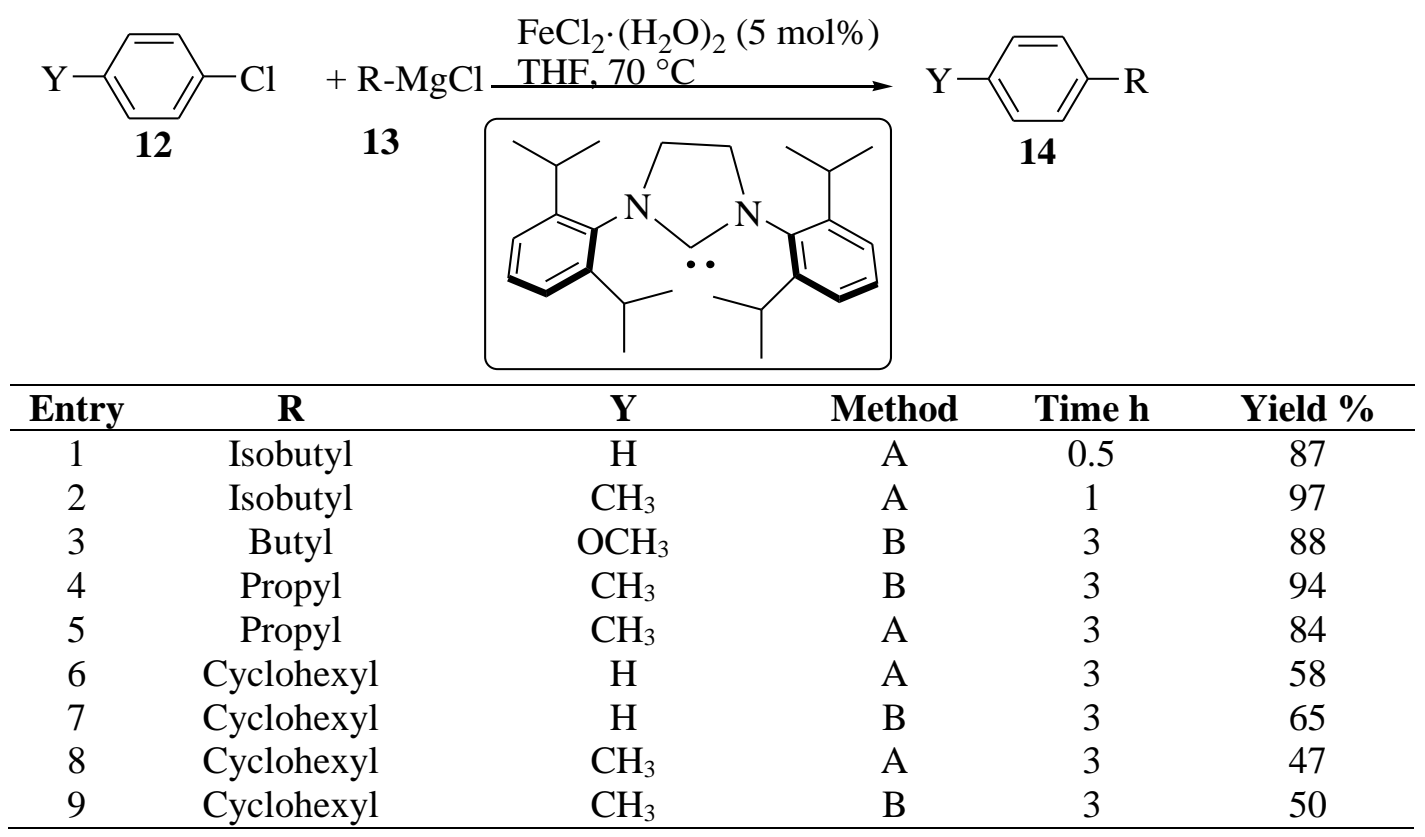

In 2013, Wang and his group demonstrated an efficient protocol for the coupling reaction of aryltrimethylammonium triflates $\mathbf{1 5}$ and alkylmagnesium reagents $\mathbf{1 6}$ catalyzed by $\mathrm{Fe}(\mathrm{acac})_{3}$ in a mixed solvent of THF and N-methyl-2-pyrrolidinone (NMP) at room temperature ${ }^{40}$. Aside from the mild reaction conditions, triumph over $\beta$-hydride elimination, which is a major challenge of using primary or secondary alkylmagnesium reagents possessing $\beta$-hydrogens, was a considerable achievement of this cross-coupling methodology. In this context, NMP as a cosolvent might play a significant role in stabilization the catalytically active iron species during cross-coupling mechanism to prevent spontaneous decomposition through $\beta$-elimination, isomerization or homocoupling. Under this optimized coupling conditions, the coupling reactions of aryltrimethylammonium triflates and alkyl magnesium reagents were carried out over only $1 \mathrm{~h}$ or shorter reaction time, generating the corresponding products in high yield ( Table 2, entries, 1-9). Ultimately, this cross-coupling protocol tolerates a broad range of functional groups including COOEt, $\mathrm{COOi}-\mathrm{Pr}, \mathrm{CONEt}_{2}, \mathrm{CN}, \mathrm{CF}_{3}$, and $\mathrm{C}-\mathrm{C}$ double bond groups. However, the authors suggested the mechanism of the $\mathrm{Fe}(\mathrm{acac})_{3}$-catalyzed reaction of aryl trimethylammonium triflate with alkylmagnesium reagents (Scheme 1). $\mathrm{Fe}(\mathrm{acac})_{3}$ is reduced by the organomagnesium reagent to produce a $\left[\mathrm{Fe}(\mathrm{MgX})_{2}\right]$ intermediates. Reaction of the catalytically active $\left[\mathrm{Fe}(\mathrm{MgX})_{2}\right]$ with aryl trimethylammonium triflate gives $\mathrm{ArFe}(\mathrm{OTf})(\mathrm{MgX})_{2}$, which is then decomposed to $\mathrm{Mg}(\mathrm{X})(\mathrm{OTf})$ and $\mathrm{ArFe}(\mathrm{MgX})$. Alkyl magnesium regent reacts with $\mathrm{ArFe}(\mathrm{MgX})$ to afford $\mathrm{ArFe}(\mathrm{R})(\mathrm{MgX})_{2}$, upon collisional activation. This complex undergoes a reductive elimination and releases the cross-coupling products.

Cook and workers reported a method for constructing $\mathrm{C}-\mathrm{C}$ bonds via the cross-coupling reaction of primary and secondary alkylmagnesium chloride nucleophiles $\mathbf{1 9}$ and aryl sulfamates and tosylates $\mathbf{1 8 \text { , }}$ catalyzed by an air stable $\mathrm{FeF}_{3} \cdot 3 \mathrm{H}_{2} \mathrm{O}$ with the aid of 1,3-bis(2,6 diisopropylphenyl)imidazolium chloride as an effective $\mathrm{N}$-heterocyclic carbene ligand giving the desired products in satisfactory yields $\mathbf{2 0}^{41}$. In general, the acyclic secondary alkylmagnesium reagents coupling partners are prone to $\beta$-hydride elimination problems to afford linear chain byproducts, resulting in reduced yields of the corresponding coupling products. Strategically, branched-to-linear selectivity ratio was controlled by using the suitable substrates and catalyst system under optimized coupling reaction conditions.

Table 2. Iron-catalyzed cross-coupling of aryltrimethylammonium triflates and alkyl magnesium reagents 


\begin{tabular}{|c|c|c|c|}
\hline \multicolumn{2}{|c|}{$\begin{array}{l}\mathrm{Ar}-\mathrm{NMe}_{3} \mathrm{OTF}+ \\
\quad \mathbf{1 5}\end{array}$} & $\frac{\mathrm{Fe}(\mathrm{acac})_{3}(10 \mathrm{~mol} \%)}{\text { THF-NMP }(7: 1), \mathrm{rt}, 1 \mathrm{~h}}$ & $\begin{array}{c}\text { Ar-R } \\
17\end{array}$ \\
\hline Entry & $\mathbf{A r}$ & $\mathbf{R}$ & Yield \% \\
\hline 1 & $p-\mathrm{EtO}_{2} \mathrm{CC}_{6} \mathrm{H}_{4}$ & $\mathrm{PhCH}_{2} \mathrm{CH}_{2} \mathrm{CH}_{2}$ & 96 \\
\hline 2 & $p-\mathrm{EtO}_{2} \mathrm{CC}_{6} \mathrm{H}_{4}$ & $n-\mathrm{C}_{4} \mathrm{H}_{9}$ & 96 \\
\hline 3 & $p-\mathrm{EtO}_{2} \mathrm{CC}_{6} \mathrm{H}_{4}$ & $n-\mathrm{C}_{8} \mathrm{H}_{17}$ & 97 \\
\hline 4 & $p$-i- $\mathrm{PrO}_{2} \mathrm{CC}_{6} \mathrm{H}_{4}$ & $\mathrm{PhCH}_{2} \mathrm{CH}_{2} \mathrm{CH}_{2}$ & 92 \\
\hline 5 & $p$-i- $\mathrm{PrO}_{2} \mathrm{CC}_{6} \mathrm{H}_{4}$ & $n-\mathrm{C}_{4} \mathrm{H}_{9}$ & 99 \\
\hline 6 & $p$-i- $\mathrm{PrO}_{2} \mathrm{CC}_{6} \mathrm{H}_{4}$ & $n-\mathrm{C}_{8} \mathrm{H}_{17}$ & 99 \\
\hline 7 & $p-\mathrm{NCC}_{6} \mathrm{H}_{4}$ & $\mathrm{PhCH}_{2} \mathrm{CH}_{2} \mathrm{CH}_{2}$ & 70 \\
\hline 8 & $p-\mathrm{CF}_{3} \mathrm{C}_{6} \mathrm{H}_{4}$ & $n-\mathrm{C}_{8} \mathrm{H}_{17}$ & 77 \\
\hline 9 & $8-\mathrm{Me}_{2} \mathrm{~N}-1-\mathrm{C}_{10} \mathrm{H}_{6}$ & $\mathrm{PhCH}_{2} \mathrm{CH}_{2} \mathrm{CH}_{2}$ & 62 \\
\hline
\end{tabular}

Table 3. The iron-catalyzed cross-coupling reaction of aryl sulfamates and tosylates with primary and secondary alkylmagnesium reagents

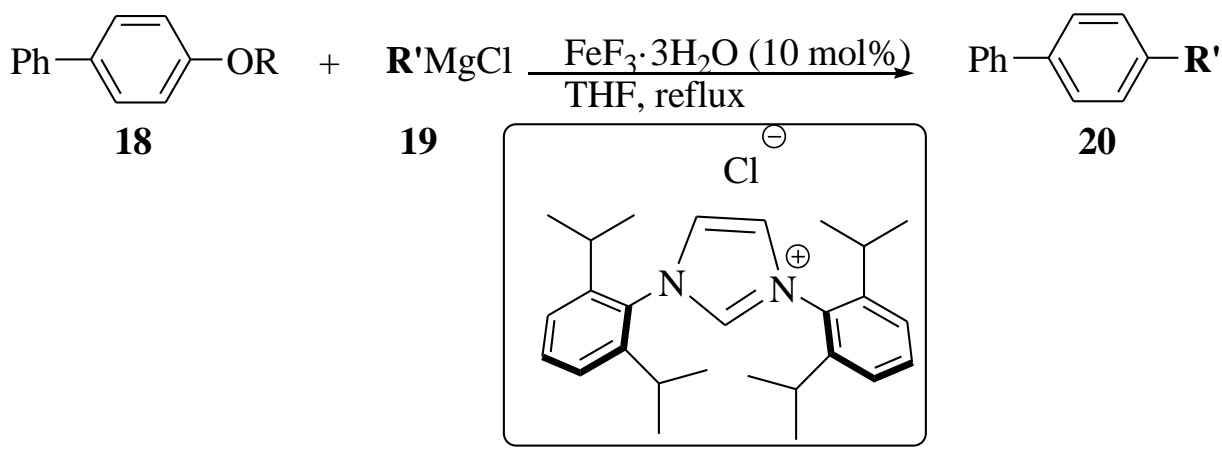

\begin{tabular}{|c|c|c|c|c|}
\hline Entry & $\mathbf{R}$ & R'MgCl & Products & Yield \% (Branched/linear ratio) \\
\hline 1 & $-\mathrm{SO}_{2} \mathrm{NMe}_{2}$ & $\mathrm{MgC}$ & & 90 \\
\hline 2 & $-\mathrm{SO}_{2} \mathrm{NMe}_{2}$ & & & 77 \\
\hline 3 & $-\mathrm{SO}_{2} \mathrm{NMe}_{2}$ & & & $65(6.5: 1)$ \\
\hline 4 & $-\mathrm{Ts}$ & $\mathrm{MgC}$ & & 74 \\
\hline 5 & $-\mathrm{Ts}$ & & & 39 \\
\hline 6 & $-\mathrm{Ts}$ & & & $50(1: 10)$ \\
\hline
\end{tabular}

However, $\mathrm{FeF}_{3} * 3 \mathrm{H}_{2} \mathrm{O}$ catalyzed coupling reaction of alkylmagnesium chloride with aryl sulfamate substrates to provide higher yields (Table 3, entries 1-2) compared to coupling reactions with aryl tosylates (entries 3-5). Coupling of isopropylmagnesium chloride with [1,1'-biphenyl]-4-yl 
dimethylsulfamate produced predominately the branched product (65\% yield, (6.5:1), entry 3), while the analogous aryl tosylate led to the formation of predominantly linear product (50\% yield, (1:10), entry 6). Surprisingly, 1,3-bis(2,6-diisopropylphenyl)-imidazol- 2-ylidene (IPr) was found to be the most effective among the other ligands such as TMEDA, NMP and phosphines, as well as other polydentate amines like bipyridine and terpyridine, which led to none of the desired products.

Table 4. Cross-coupling reactions of cyclohexyl magnesium bromide / $\mathrm{LiBr}$ adduct and various fluorinated bromobenzene derivatives using $\mathrm{FeCl}_{2} \mathrm{dppe}$ and $\mathrm{FeCl}_{2} \mathrm{dppp}$ catalysts with yields<smiles>[Y16]C1CCCCC1Br</smiles>

21<smiles>Fc1ccc(Br)cc1</smiles>

22

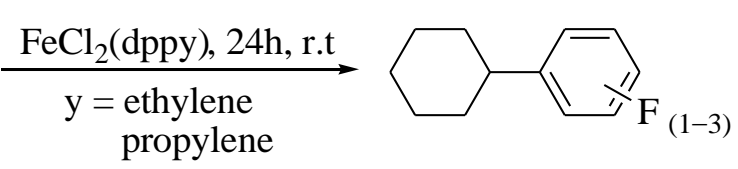

23

\begin{tabular}{lcc}
\hline Entry & FeCl $_{2}$ dppe \% & FeCl 2 dpp \% $^{2}$ \\
\hline
\end{tabular}

The bite angle of bidentate phosphine ligands is a significant additional parameter that has powerful impact on the catalytic activity of the metal catalyst in cross-coupling reactions. In 2013, Dahadha and Imhof investigated the influence of the bite angle of the diphosphine based on alkane backbone ligands through coupling of cyclohexylmagnesium bromide $\mathbf{2 1}$ with fluorinated bromobenzene substrates 22 in the presence of one of the following iron-phosphine complexes; 1,2bis(diphenyphosphino)ethane]dichloroiron(II) $\mathrm{FeCl}_{2}$ (dppe) and 1,3-bis(diphenyphosphino)propane]dichloroiron(II) $\mathrm{FeCl}_{2}$ (dppp) as promising catalysts under mild reaction conditions to afford the crosscoupled products $\mathbf{2 3}^{42}$. Based upon the results, $\mathrm{FeCl}_{2}(\mathrm{dppp})$ catalyst gave slightly higher yields of the coupled products compared to $\mathrm{FeCl}_{2}$ (dppe) catalyst (Table 4, entries 1-4). Undoubtedly, this behavior is attributable mainly to the effect of increasing the chelate ring size of bidentate phosphine ligands, which is the result of widened bite angles, and an increased flexibility of the backbone chain. And, also, this effect might have a major role in facilitating the reductive elimination process during the coupling mechanism to optimize greatly the performance of the iron catalyst. On the other hand, under the same optimized coupling reaction using 1,1- bis(diphenylphosphino)methane]dichloroiron(II) $\mathrm{FeCl}_{2}$ (dppm) as catalyst gave the cross coupled products in a very low yield.

As known to all, the best electrophilic substrates for cross-coupling reactions are aryl (alkenyl) iodides, bromides, and triflates. Recently, the use of distinctive ligands allowed the scope of catalyzed coupling reactions to extend to aryl chlorides, which are the most attractive starting materials due to their 
low cost and ready availability on a large scale. In 2013, Fox and his group designed a protocol for coupling of activated aryl chlorides $\mathbf{2 4}$ and ethylmagnesium chloride $\mathbf{2 5}$ in the presence of the cheap and readily removed ligands such as tetramethylethylenediamine (TMEDA) or hexamethylenetetramine (HMTA) as well as employing 1-methyl-2-pyrollidinone (NMP) as an effective cosolvent with 5 mol \% catalyst loading of $\mathrm{Fe}(\mathrm{acac})_{3}$ to give high yields of the coupled products with no side reactions observed at ambient conditions (Table 5, entries1-3). It is worth noting that in the absence of these ligands, the coupling of methyl 4-chlorobenzoate and ethylmagnesium chloride, catalyzed by $\mathrm{Fe}(\mathrm{acac})_{3}$, afforded methyl 4-ethylbenzoate 26 with relatively lower yield ${ }^{43}$. Compared to N-heterocyclic carbene (NHC), type ligands were reported to require coupling conditions more forcing such as long reaction times and high temperatures. TMEDA can be used at mild reaction conditions producing good yields of corresponding coupled products.

Table 5. Optimization of the synthesis of ester $\mathbf{2 6}$ using various ligands

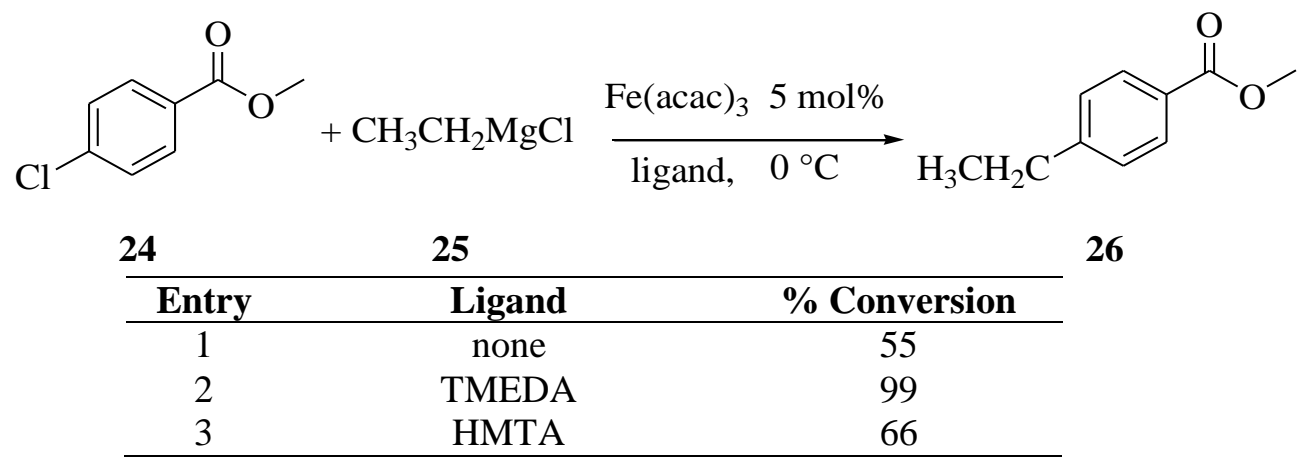

In the past years, great progress has been made in the development of iron-catalyzed cross coupling reactions, including a wide spectrum of the electrophilic substrate under various reaction conditions. In 2015, Cun Wang and coworkers designed an efficient and fast method to prepare substituted pyrimidines in synthetically advantageous yields through cross-coupling of pyrimidin-2-yl tosylates 27 and alkylmagnesium reagents $\mathbf{2 8}$, catalyzed by low-cost and abundantly available $\mathrm{FeCl}_{3}$ with the help of $\mathrm{N}$-methylpyrrolidone (NMP) as a cosolvent at very low temperature within $15 \mathrm{~min}^{44}$. However, the use of NMP as a co-solvent in iron catalyzed coupling reactions, because of its significant role in the stabilization of the major organoiron species, generated in situ reactions of simple ferric salts with Grignard reagent leading to high yield of cross-coupled products ${ }^{45}$. In this optimized cross-coupling protocol, electronic properties of electron-donating and electron-withdrawing groups on pyrimidin-2-yl tosylates 27 had little influence on the reaction (Scheme 4, 29a-29m). However, using arylmagnesium reagents as nucleophile to couple with pyrimidin-2-yl tosylates required both a high $\mathrm{Fe}(\mathrm{acac})_{3}$ loading catalyst, where $\mathrm{FeCl}_{3}$ was ineffective as a catalyst in this case, and TMEDA as free ligand to produce the corresponding coupled products in $41-55 \%$ yields. As limitation of this coupling methodology, phynel / benzylmagnesium bromide did not couple with pyrimidin-2-yl tosylate.

In 2015, Agata and coworkers demonstrated that iron(III)fluoride/1,3-bis(2,6 diisopropylphenyl)imidazolin- 2-ylidene (SIPr) can act as a powerful catalyst system for carbon-carbon bond formation by coupling of deactivated aryl chlorides 30 and alkylmagnesium reagents $\mathbf{3 1}^{46}$. In this work, the electron rich and sterically hindered 1-chloro-2-methoxybenzene smoothly underwent coupling reaction with methylmagnesium chloride by virtue of the use of iron(III)fluoride/SIPr catalyst system to provide the coupled product in an excellent yield (Table 6, entry 1). Whilst the reaction of more electron rich 1-chloro-3,5-dimethoxybenzene and methylmagnesium reagent proceeded slowly to give the corresponding coupled product in $30 \%$ yield (entry 2 ). 
<smiles>[X]c1ccc(-c2nc(OC(F)(F)F)nc(C)c2C(=O)OCC)cc1</smiles>

27<smiles>[X]c1ccc(-c2nc(CC)nc(C)c2C(=O)OCC)cc1</smiles>

29a, $X=\mathrm{H} \quad 77 \%$

29b, $\mathrm{X}=\mathrm{OMe} \quad 83 \%$

29c, $X=\mathrm{Me} \quad 81 \%$

29d, $X=F \quad 68 \%$

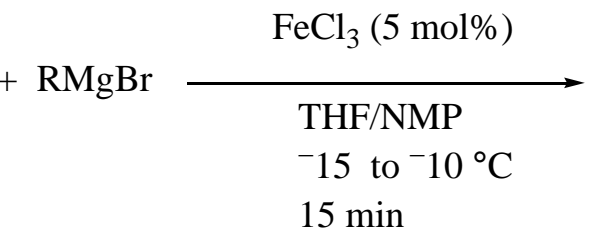

28<smiles>[X]c1ccc(-c2nc([R])nc(C)c2C(=O)OCC)cc1</smiles>

29<smiles>[X]c1ccc(-c2nc([AlH2])nc(C)c2C(=O)OCC)cc1</smiles>

29e, $\mathrm{X}=\mathrm{H} \quad 69 \%$

29f, $X=\mathrm{OMe} \quad 81 \%$

29g, $\mathrm{X}=\mathrm{Me} \quad 79 \%$

29h, $X=F \quad 65 \%$<smiles>[X]c1ccc(-c2nc(O[Na])nc(C)c2C(=O)OCC)cc1</smiles>

29i， $\mathrm{X}=\mathrm{H} \quad 78 \%$

29j, $X=O M e \quad 85 \%$

29k, $\mathrm{X}=\mathrm{Me} \quad 86 \%$

29m, $X=F \quad 65 \%$

Scheme 4. Iron-catalyzed cross-couplings of pyrimidin-2-yl tosylates with alkylmagnesium reagents

On the other hand, electronically neutral 4-chlorobiphenyl reacted effectively with the methylmagnesium bromide affording coupled product in $99 \%$ yield (entry 3 ). The desired methylation product was obtained in $93 \%$ yield when 3-chloro-N,N-dimethylbenzenamine was used as a substrate (entry 4). Strikingly, often $\mathrm{FeF}_{3}$ in combination with SIPr ligand acted as an effective catalyst in coupling reactions. This reaction was achieved employing lower loading $\mathrm{FeF}_{3}$ in excellent yields without serous $\beta$-hydride elimination problems including wider scope of the substrates compared to the coupling methodology developed by Cook (Table 3), in which $\mathrm{FeF}_{3} \bullet 3 \mathrm{H}_{2} \mathrm{O}$ catalyzed coupling of and aryl sulfamates and tosylates with alkylmagnesium halides.

Iron has emerged as one of the very few metals that have been successfully catalyzed carboncarbon coupling to synthesize pharmaceuticals and natural products due to its ability to couple a variety of the electrophilic substrates with organomagnesium halides under optimal reaction conditions. In 2016, Fürstner and his coworkers reported a novel methodology for $\mathrm{Csp}^{3}-\mathrm{Csp}^{3}$ bond formation via crosscoupling of 1-alkynylcyclopropyl tosylates 33 carrying phenyl, butyl, $\left(\mathrm{CH}_{2}\right)_{2} \mathrm{OBn}$ and $\mathrm{CH}_{2} \mathrm{OPh}$ groups with various primary alkyl or aryl organomagnesium halides $\mathbf{3 4}$ by using iron(III) acetylacetonate (5 mol\%) in THF at $-20{ }^{\circ} \mathrm{C}$ to room temperature to generate a wide spectrum of distinguished organic molecules containing quaternary carbon centers $\mathbf{3 5}$ in good to excellent yields (Table 7, entries 1-4) ${ }^{47}$. This methodology was applied to the synthesis of a series of building blocks for anti-HIV, hepatitis C drugs and for crop protection purposes. Obviously, the reaction is limited to 1-alkynylcyclopropyl tosylates. A suitable substrate partner was proposed to proceed smoothly through cross coupling relations mediated by an iron catalyst to give the desired products, whilst the other propargyl derivatives resulted in allene formation as byproducts in high yields. 
Table 6. Iron (III) fluoride/SIPr-catalyzed cross coupling reaction of aryl chlorides with methylmagnesium bromide

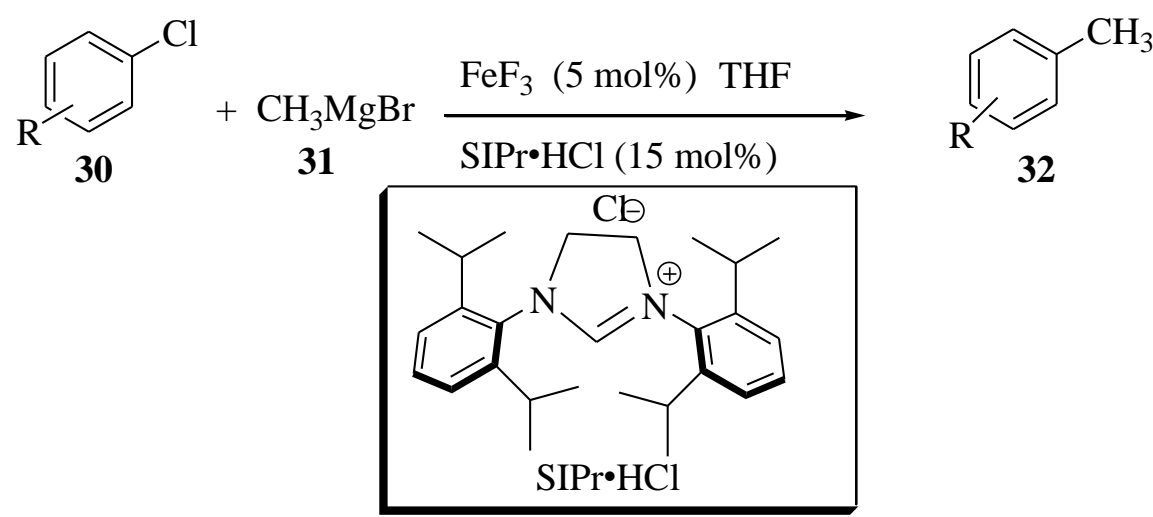

Entry

In 2016, Frantz and coworkers reported highly stereoselective iron-catalyzed cross-coupling reaction between stereodefined enol carbamates $\mathbf{3 6}$ and alkylmagnesium reagents $\mathbf{3 7}$ to give an array of tri- and tetra-substituted acrylates $\mathbf{3 8}$ in excellent yields and much higher stereochemical purities ${ }^{48}$. The coupling reactions of alkylmagnesium reagents with $(E)$-enol carbamates catalyzed by $\mathrm{FeCl}_{3}$ at $-78{ }^{\circ} \mathrm{C}$ in the presence of NMP in THF as a crucial and effective cosolvent generated high yields of $(E)$ - tri- and tetrasubstituted acrylates with an excellent selectivity in $E / Z$ ratios ranging from 10:1 to 117:1 (Table 8, entries 1-5). Broad scope of desired (Z)- tri- and tetra-substituted acrylates $\mathbf{4 1}$ were produced in high yields and $Z / E$ selectivities ranging from 25:1 to 50:1 through $\mathrm{FeCl}_{3}$ mediated cross-coupling reactions of (Z)-enol carbamates 39 with alkylmagnesium bromides $\mathbf{4 0}$ at $-40{ }^{\circ} \mathrm{C}$ without need to utilize NMP as a cosolvent (Table 9, entries 1-4). Additionally, these coupling reactions are generally readily scalable and tolerant to a wide range of functional groups such as acetals, ethers, silanes, terminal alkynes and alkenes, protected amines and primary bromides. 
Table 7. Iron-catalyzed cross-coupling of different organomagnesium reagents with 1alkynylcyclopropyl tosylates

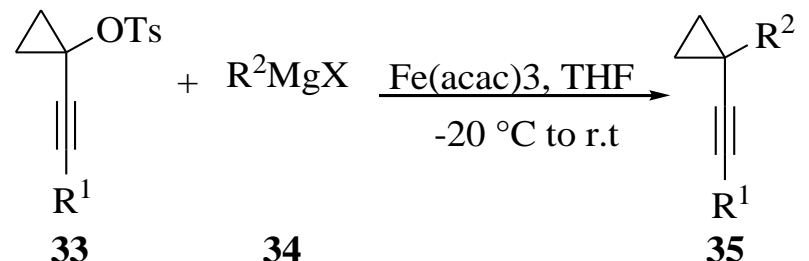

\begin{tabular}{|c|c|c|c|}
\hline Entries & Products & $\mathbf{R}^{1}$ & $\frac{35}{\text { Yield \% }}$ \\
\hline 1 & & $\begin{array}{c}\mathrm{Ph} \\
\left(\mathrm{CH}_{2}\right)_{2} \mathrm{OBn}\end{array}$ & $\begin{array}{l}70 \\
76\end{array}$ \\
\hline
\end{tabular}

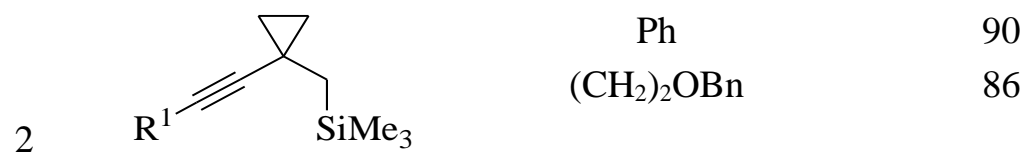

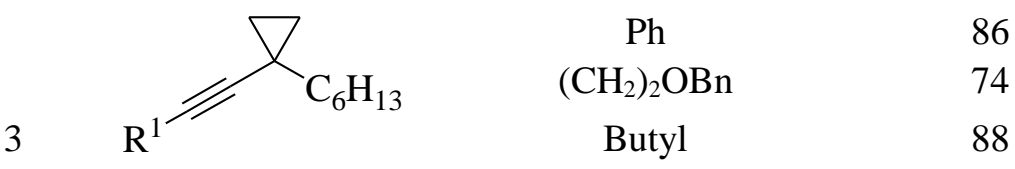

$4 . \begin{array}{cc}\mathrm{Ph} & 76 \\ \left(\mathrm{CH}_{2}\right)_{2} \mathrm{OBn} & 73 \\ \mathrm{CH}_{2} \mathrm{OPh} & 76\end{array}$

Table 8. Preliminary substrate scope for the iron-catalyzed cross-coupling of (E)-enol carbamates and alkylmagnesium reagents

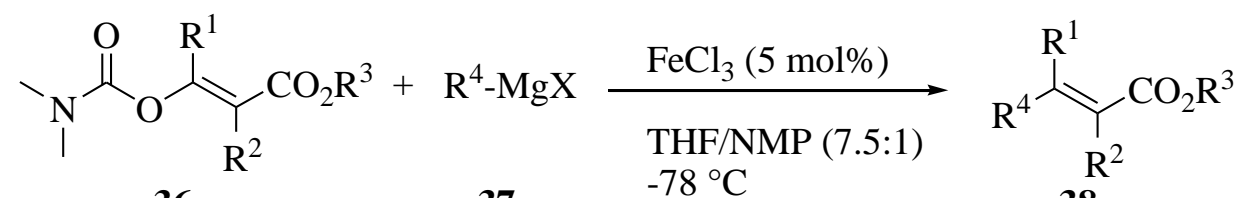

36

37

38

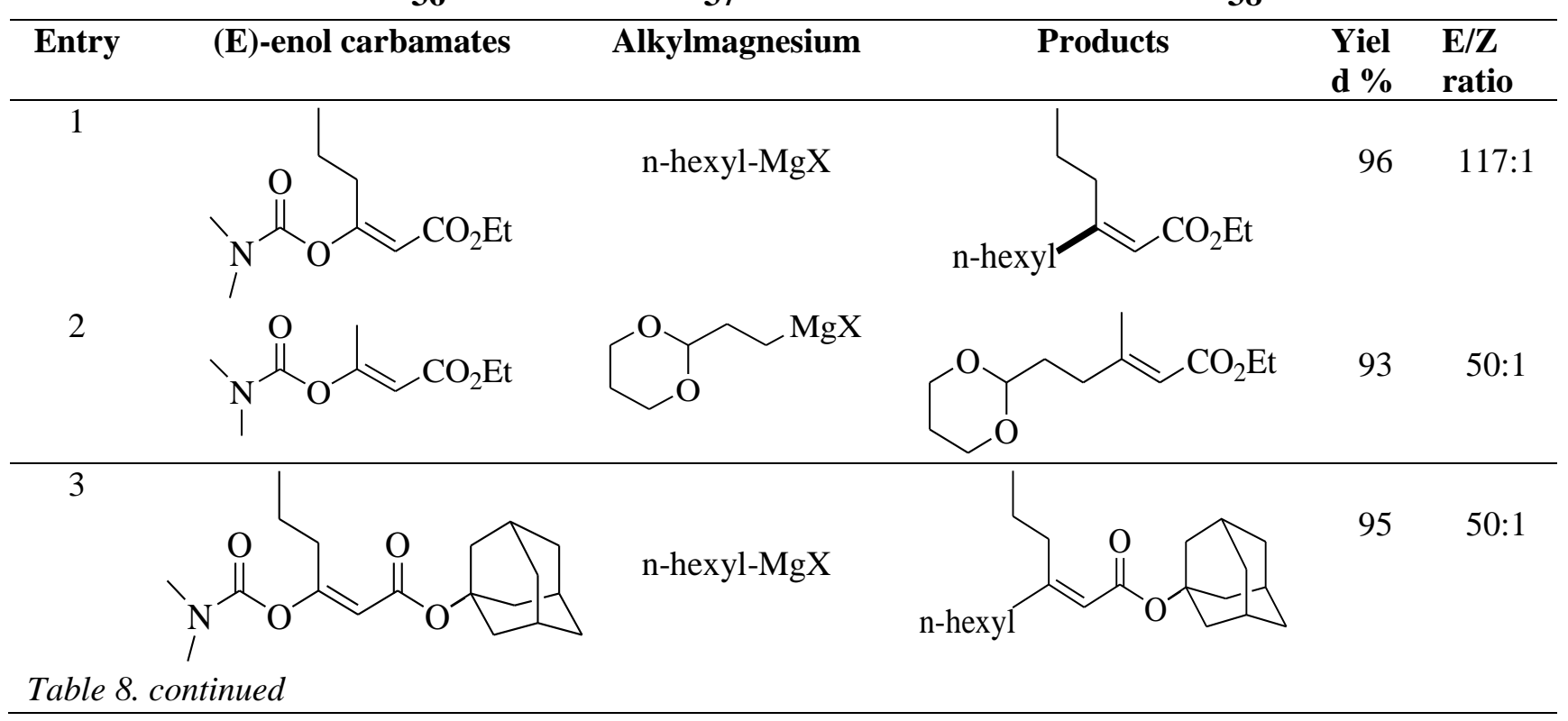


4<smiles>C=CCCCC(OC(=O)N(C)C)=C(C)C(=O)OCC</smiles>
n-hexyl-MgX<smiles>C=CCCC/C(C(=O)OCC)=C(/C)[AlH2]</smiles>

5<smiles>CCOC(=O)/C=C(\C)OC(=O)N(C)C</smiles><smiles>[X]CCc1ccccc1</smiles><smiles>CCOC(=O)/C=C(\C)CCc1ccccc1</smiles>

Table 9. Preliminary substrate scope for the iron-catalyzed cross-coupling of (Z)-enol carbamates and alkymagnesium reagents

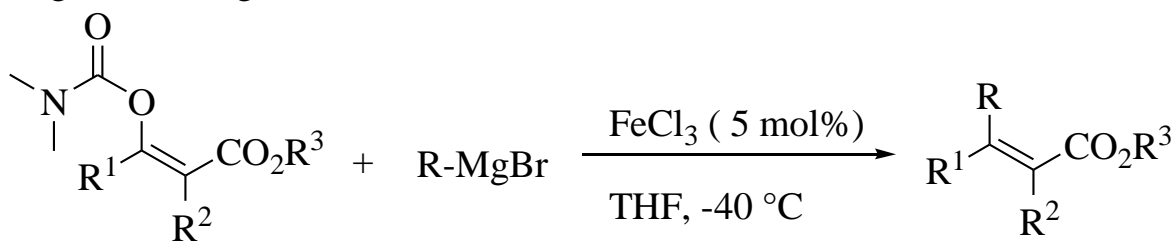

39

40

41

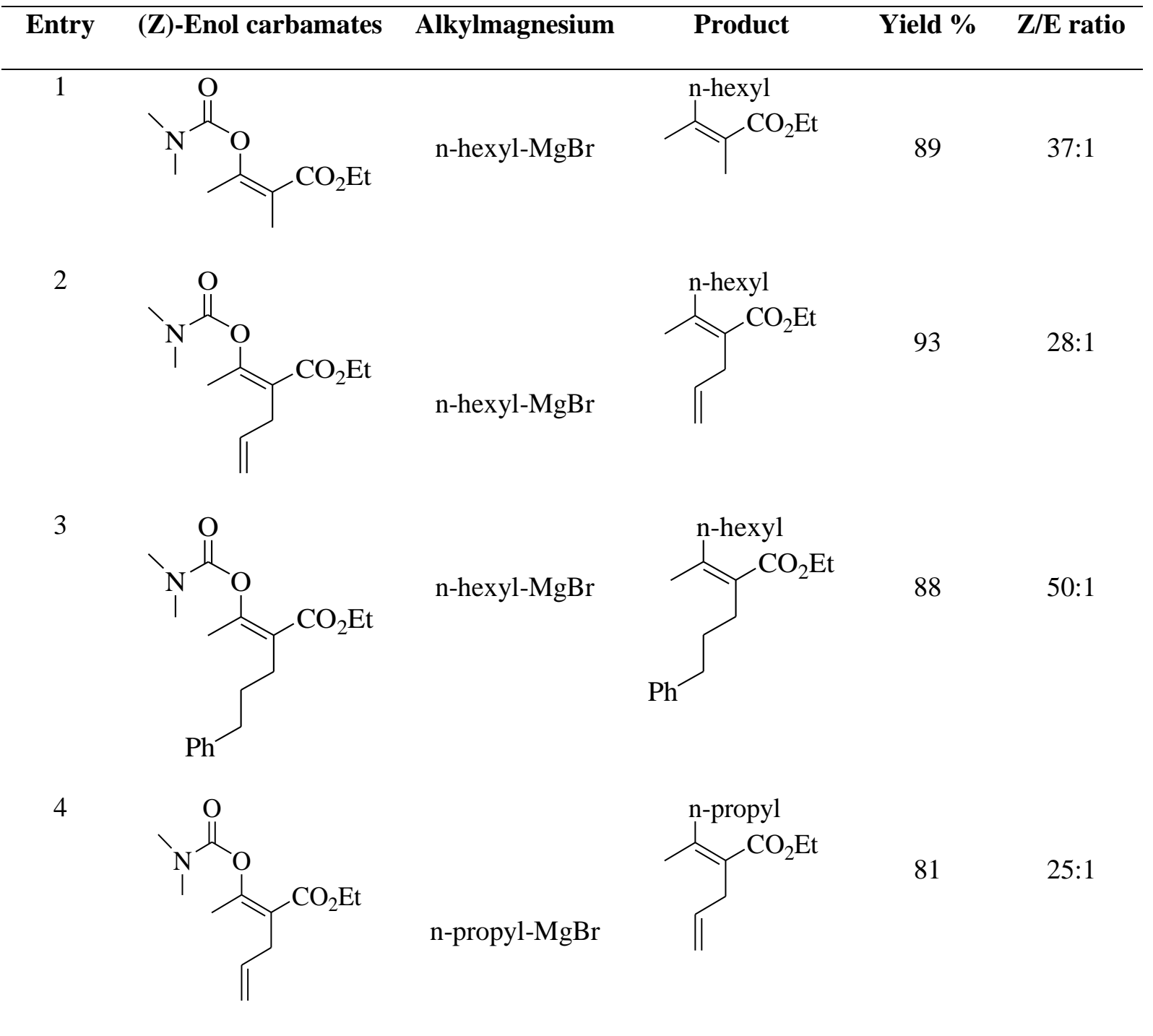


Recently, the attention of researchers has been drawn towards the use of efficient, more environmentally benign and sustainable alternatives to the highly reprotoxic NMP in iron-catalyzed cross coupling reactions. In this context, in 2017, Michal Szostak and his group successfully developed iron with cyclic urea ligands (DMI, DMPU; DMI = 1,3-dimethyl-2-imidazolidinone, DMPU = 1,3-dimethyl3,4,5,6- tetrahydro-2(1H)-pyrimidinone) as a powerful catalyst system for $\mathrm{Csp}^{2}-\mathrm{Csp}^{3}$ bond formation via coupling reaction of aryl chlorides $\mathbf{4 2}$ and tosylates with alkylmagnesium reagents $\mathbf{4 3}$ under mild and operationally-simple conditions furnishing relatively high yields of desired products $\mathbf{4 4}$ (Table 10, entries $1-5)^{49}$. In this respect, especially the use of cyclic ureas (DMI, DMPU) has significantly contributed to the success of the cross-coupling reactions and opened the way to develop environmentally-friendly methodologies to employ in the synthesis of pharmaceutical intermediates. Compared to aryl chloride substrates mentioned above, this coupling protocol was particularly used to form $\mathrm{Csp}^{2}-\mathrm{Csp}^{3}$ bonds depending on activated and less sterically hindered aryl chloride substrates.

Table 10. Scope of Fe-catalyzed coupling using benign ligands

$$
\operatorname{Ar}(\mathrm{Het})-\mathrm{Cl}+\mathrm{C}_{14} \mathrm{H}_{29} \mathrm{MgCl} \underset{\text { Ligand, THF, } 0{ }^{\circ} \mathrm{C}}{\stackrel{\mathrm{Fe}(\mathrm{acac})_{3}}{\longrightarrow}} \operatorname{Ar}(\mathrm{Het})-\mathrm{C}_{14} \mathrm{H}_{29}
$$

\begin{tabular}{|c|c|c|c|}
\hline Entry & Substrate & Ligand & Yield \% \\
\hline \multirow[t]{3}{*}{1} & & 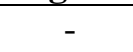 & 41 \\
\hline & & DMPU & 90 \\
\hline & & DMI & 96 \\
\hline \multirow[t]{3}{*}{2} & & - & 88 \\
\hline & & DMPU & 95 \\
\hline & & DMI & 93 \\
\hline \multirow[t]{3}{*}{3} & & - & 16 \\
\hline & & DMPU & 92 \\
\hline & & DMI & 89 \\
\hline \multirow[t]{3}{*}{4} & & - & 29 \\
\hline & & DMPU & 93 \\
\hline & & DMI & 88 \\
\hline \multirow[t]{3}{*}{5} & & - & 28 \\
\hline & & DMPU & 94 \\
\hline & 0 & DMI & 88 \\
\hline
\end{tabular}

Alkylated polyaromatics are often employed in pharmaceutical industry, high performance fluid applications and organic electronic materials. In 2017, Szostak and his colleague successfully prepared alkylated polyaromatics $\mathbf{4 7}$ by coupling alkylmagnesium chlorides possessing $\beta$-hydrogen atoms with polyaromatic tosylates using $\mathrm{Fe}(\mathrm{acac})_{3} / \mathrm{NMP}$ catalyst system under very mild, operationally practical conditions ${ }^{50}$. However, butylmagnesium chloride $\mathbf{4 6}$ underwent smoothly cross coupling with 1-naphthyl, 2-naphthyl and phenanthrenyl tosylate $\mathbf{4 5}$ to provide the coupled products in satisfactory yields (Table 11, entries, 1-3). Sensitive functional groups such as nitriles and esters were tolerated and the cross-coupling products were formed in 78-84\% yields (entries 4-5). Thus, compared to Table 3, the coupling reaction herein was successfully performed with low catalyst loading at milder reaction conditions. In this context, these mild coupling conditions will permit the synthesis of functionalized aromatic compounds with a 
wide spectrum of functional group tolerance, resulting in a considerable simplification in the preparation of biologically active unnatural compounds.

Table 11. Coupling alkylmagnesium halides with polyaromatic tosylates using Fe(acac)3/NMP catalyst system

$$
\begin{array}{ccc}
\mathrm{Ar}-\mathrm{OTs} & +\underset{\mathrm{C}_{4} \mathrm{H}_{9}-\mathrm{MgCl}}{\mathbf{4 5}} \underset{\mathbf{4 6}}{\frac{\mathrm{Fe}(\mathrm{acac})_{3}}{\mathrm{NMP}, \mathrm{THF}, 23{ }^{\circ} \mathrm{C}}} & \mathrm{Ar}-\mathrm{C}_{4} \mathrm{H}_{9} \\
\mathbf{4 7} & &
\end{array}
$$

Entry Substrate

In 2018, Diego J. Cardenas designed a novel catalyst system using $\mathrm{Fe}(\mathrm{OAc})_{2}$ in combination with 1,3-dimesityl-1H-imidazol-3-ium chloride for an efficient and regioselective cross-coupling reaction of propargyl bromides 48 with alkylmagnesium bromide 49 in THF at $-78{ }^{\circ} \mathrm{C}$ in 1 hour to afford either desired propargyl 37 or allene $\mathbf{3 8}$ derivatives (Table 12, entries $1-4)^{51}$. Primary propargylic substrates with various substituents underwent cross coupling with (1,3-dioxan-2-ylethyl)magnesium bromide yielding desired regioselective propargyl coupling products in modest yields regardless of the substituents on the benzene ring. On the other hand, in other cases, especially in the existence of bulky groups such as tert-butyl, $n$-octyl and cyclohexyl on the propargylic position, the reaction tended to favor formation of the allene coupling product 53 by construction $\mathrm{C}-\mathrm{C}$ bond at the distal carbon (Scheme 5). According to a previous research, achieved by Fürstner and his coworkers, high yields of the corresponding coupled products with quaternary carbon centers were produced using a broader scope of both 1alkynylcyclopropyl tosylates with alkyl or aryl organomagnesium halides with the formation of much lower amounts of the allenes byproducts compared to this coupling protocols, which also required severe conditions in the presence of $\mathrm{N}$-heterocyclic carbene ligand. 
Table 12. Scope and regioselectivity for primary propargyl derivatives

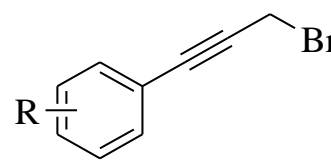

$\mathrm{Fe}(\mathrm{OAc}) 2(2,5 \mathrm{~mol} \%)$ IMes. $\mathrm{HCl}(6 \mathrm{~mol} \%)$<smiles>CC(C)(C)CCCC1OCCCO1</smiles>

48<smiles>[R]c1ccc(C#CCCCC2C[CH-]CCO2)cc1</smiles>

50<smiles>[R]c1ccc(C(=C=C)CCC2OCCCO2)cc1</smiles>

51

\begin{tabular}{cccc}
\hline Entry & $\mathbf{R}$ & Ratio & Yield \% \\
\hline 1 & 3-OCH & $93: 7$ & 51 \\
2 & 4-CN & $92: 8$ & 66 \\
3 & 4-Me & $98: 2$ & 48 \\
4 & 2-Naphthyl & $93: 7$ & 46 \\
\hline
\end{tabular}<smiles>CC(C)(C)C(Br)C#Cc1ccccc1</smiles>

52
$\mathrm{Fe}(\mathrm{OAc})_{2}(2,5 \mathrm{~mol} \%)$

IMes. $\mathrm{HCl}(6 \mathrm{~mol} \%)$<smiles>CCCC1OCCCO1</smiles>

49<smiles>[R][R]1cccc(C(=C=CC(C)(C)C)CCC2OCCCO2)c1</smiles>

53, $42 \%$

Scheme 5. Reaction of tert-butyl-substituted propargyl bromide is regioselective

Aromatic amide derivatives are among the most significant, predominant and versatile building blocks in pharmaceuticals, agrochemicals and other biologically-active molecules due to the presence of amide bonds.

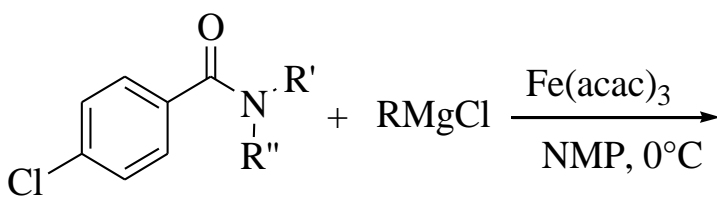

54<smiles>CCCCCCCCCCCCCCCCCCCCCCCCC</smiles>

56a, $94 \%$<smiles>CCOCCCCCC1CCCCC1c1ccc(C(=O)N2CCOCC2)cc1</smiles>

55<smiles>CCCCCCc1ccc(C(=O)N(C)C)cc1</smiles>

56b, $93 \%$<smiles>CN(C)C(=O)c1ccc(CCc2ccccc2)cc1</smiles>

56e, $62 \%$<smiles>[R]c1ccc(C(=O)N([R])[R])cc1</smiles>

56

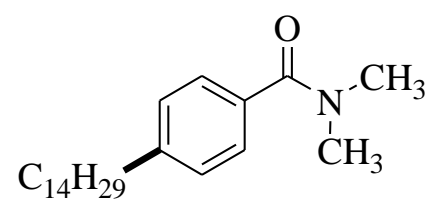

56c, $94 \%$<smiles>CC(C)c1ccc(C(=O)N(C)C)cc1</smiles>

56f, $53 \%$

Scheme 6. Iron-catalyzed cross-coupling of amides with alkylmagnesium reagents

Table 13. Iron catalyzed coupling of chlorobenzosulfonamides with alkylmagnesium reagents 


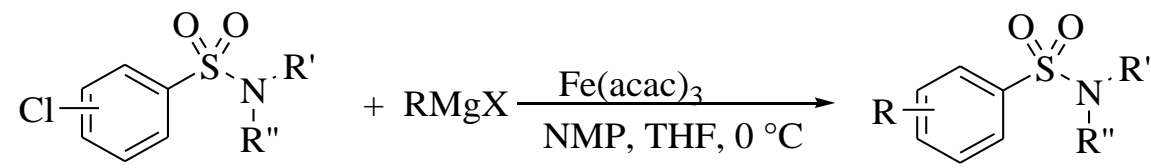

57

58

59

\begin{tabular}{ccccc}
\hline Entry & Substrate & Product & Yield \% \\
\hline 1 & &
\end{tabular}

2<smiles>O=S(=O)(c1ccc(Cl)cc1)N1CCCC1</smiles><smiles>CCc1ccc(S(=O)(=O)N2CCCC2)cc1</smiles>

95

3<smiles>CC(C)N(C(C)C)S(=O)(=O)c1ccc(Cl)cc1</smiles><smiles>CCc1ccc(S(=O)(=O)N(C(C)C)C(C)C)cc1</smiles>

4<smiles>CN(c1ccccc1)S(=O)(=O)c1ccc(Cl)cc1</smiles><smiles>CCc1ccc(S(=O)(=O)N(C)c2ccccc2)cc1</smiles>
98

5<smiles>CN(Cc1ccccc1)S(=O)(=O)c1ccc(Cl)cc1</smiles><smiles>CCc1ccc(S(=O)(=O)N(C)Cc2ccccc2)cc1</smiles>

6<smiles>CN(C)S(=O)(=O)c1ccc(Cl)cc1</smiles><smiles>CN(C)S(=O)(=O)c1ccc(C2CCCCC2)cc1</smiles><smiles>CN(C)S(=O)(=O)c1ccc(Cl)cc1</smiles><smiles>CN(C)S(=O)(=O)c1ccc(CCc2ccccc2)cc1</smiles>

In 2019, Michal Szostak et al. designed an efficient method to produce valuable alkyl-amides $\mathbf{5 6}$ through coupling of chlorobenzamides $\mathbf{5 4}$ with alkylmagnesium chlorides 55, catalyzed by iron-NMP reagent system at $0{ }^{\circ} \mathrm{C}$ within 10 minutes, which gave the corresponding coupled products in good to excellent 
yields without occurring side products arising from competing beta-hydride elimination and dimerization processes (Scheme 6, 56a-56f $)^{52}$.

Michal Szostak et al. continued their considerable efforts to develop the efficiency of iron catalysts in $\mathrm{C}-\mathrm{C}$ coupling reactions. In 2019, they carried out fast cross coupling of chlorobenzosulfonamides $\mathbf{5 7}$ with alkylmagnesium reagents $\mathbf{5 8}$ under mild and sustainable conditions with the help of $\mathrm{Fe}(\mathrm{acac})_{3}$ to produce alkylated benzosulfonamides $\mathbf{5 9}$ in excellent yields (Table 13, entries $1-7)^{53}$. Alkylated benzosulfonamides have been used substantially in the production of antibacterial, hypoglycaemic, diuretic and antihypertensive drugs. However, building upon this protocol, the electronic properties and steric hindrance of the groups on nitrogen atom of sulfonamides, such as methyl, ethyl, isopropyl, phenyl and benzyl had little influence on the coupling reaction. Compared to the previous method developed by Michal Szostak et al., illustrated in Scheme 6, although the coupling reaction times are similar, the coupling reaction of chlorobenzosulfonamide substrates with alkylmagnesium reagents is more efficient than coupling of chlorobenzamides with alkyl or arylmagnesium reagents under the same reaction conditions.

Table 14. Scope of the iron-catalyzed cross-coupling between alkynyl chlorides and alkyl magnesium reagents
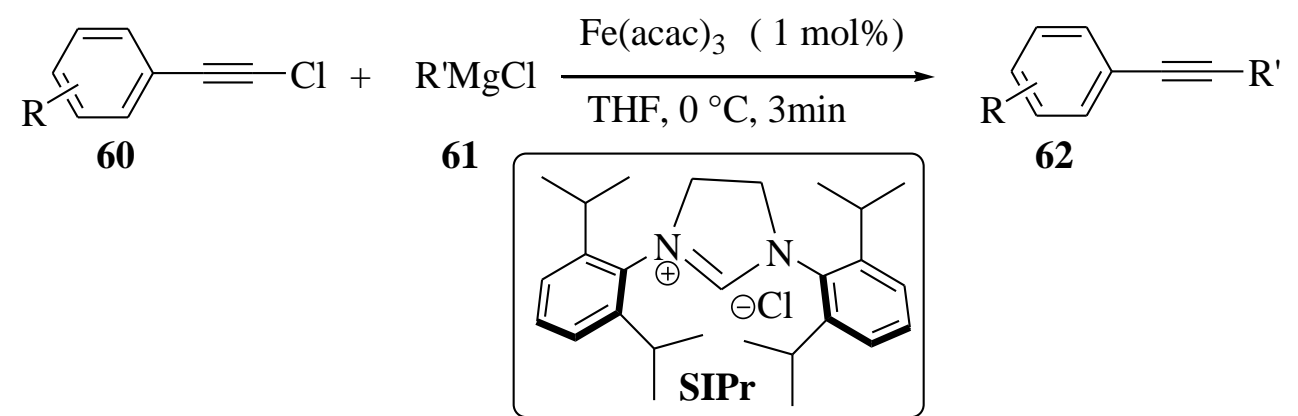

62

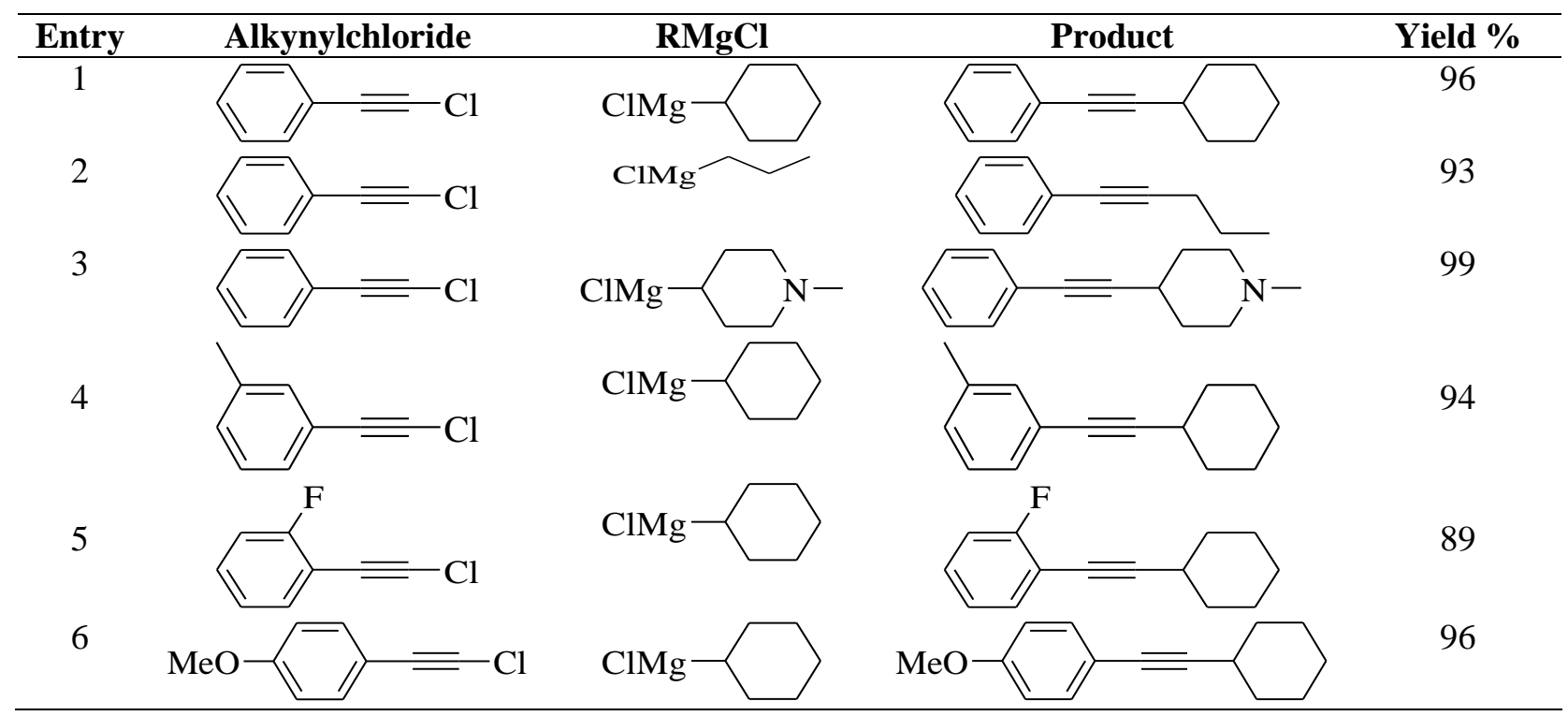

Noël and coworkers demonstrated an efficient and fast method for $\mathrm{C}\left(s p^{3}\right)-\mathrm{C}(s p)$ and $\mathrm{C}\left(s p^{3}\right)$ $-\mathrm{C}\left(s p^{2}\right)$ bond formation via iron catalyzed cross-coupling reactions of alkylmagnesium reagents with alkynyl and styrenyl chlorides in the presence of $1 \mathrm{~mol} \% \mathrm{Fe}(\mathrm{acac})_{3}$ and $2 \mathrm{~mol} \% \mathrm{SIPr}-\mathrm{HCl}$ as a catalyst system in THF at $0{ }^{\circ} \mathrm{C}^{54}$. Regardless, the coupling neutral, poor and rich alkynyl chloride $\mathbf{6 0}$ with alkylmagnesium chloride $\mathbf{6 1}$ gave the corresponding products in excellent yields (Table 14, entries 1-6). Interestingly, in the absence of any supporting ligands, the reaction of functionalized styrenyl chlorides 63 with cyclohexylmagnesium reagents 64 was efficiently carried out at room temperature to give the coupled products $\mathbf{6 5}$ in high yields and in shorter reaction time. Additionally, the reaction was found to 
be compatible with the substrates bearing electron-donating or electron withdrawing groups (Table 15, entries 1-4). In this regard, the author also reported another more efficient coupling protocol through the synthesis of organomagnesium reagents in a telescoped flow process. Then the coupling reaction was carried out in the same flow continuous system under mild conditions with loading of $\mathrm{Fe}(\mathrm{acac})_{3}$ catalyst as low as $1 \mathrm{~mol} \%$ in the absence of an NHC ligand to give the corresponding cross-coupled products in 95-98 \% isolated yields, which required only 30-60 s as residence time in the microreactor. Hence, compared to the classical coupling method, the yield and selectivity in a telescoped flow process was systematically higher due the safe control of the exotherm of the reaction, which can be attributed to the increased surface-to volume ratio, and to the enhanced mixing efficiency in the microreactor.

Table 15. Scope of the iron-catalyzed cross-coupling between styrenyl chlorides and alkylmagnesium reagents<smiles>[R]c1ccc(C=CCl)cc1</smiles>

63<smiles>CC1CCCCC1</smiles>

64

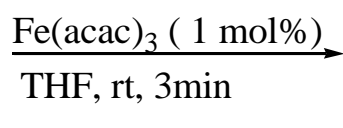

$\mathrm{R}$<smiles>[R]C=Cc1cccc([R])c1</smiles>

65

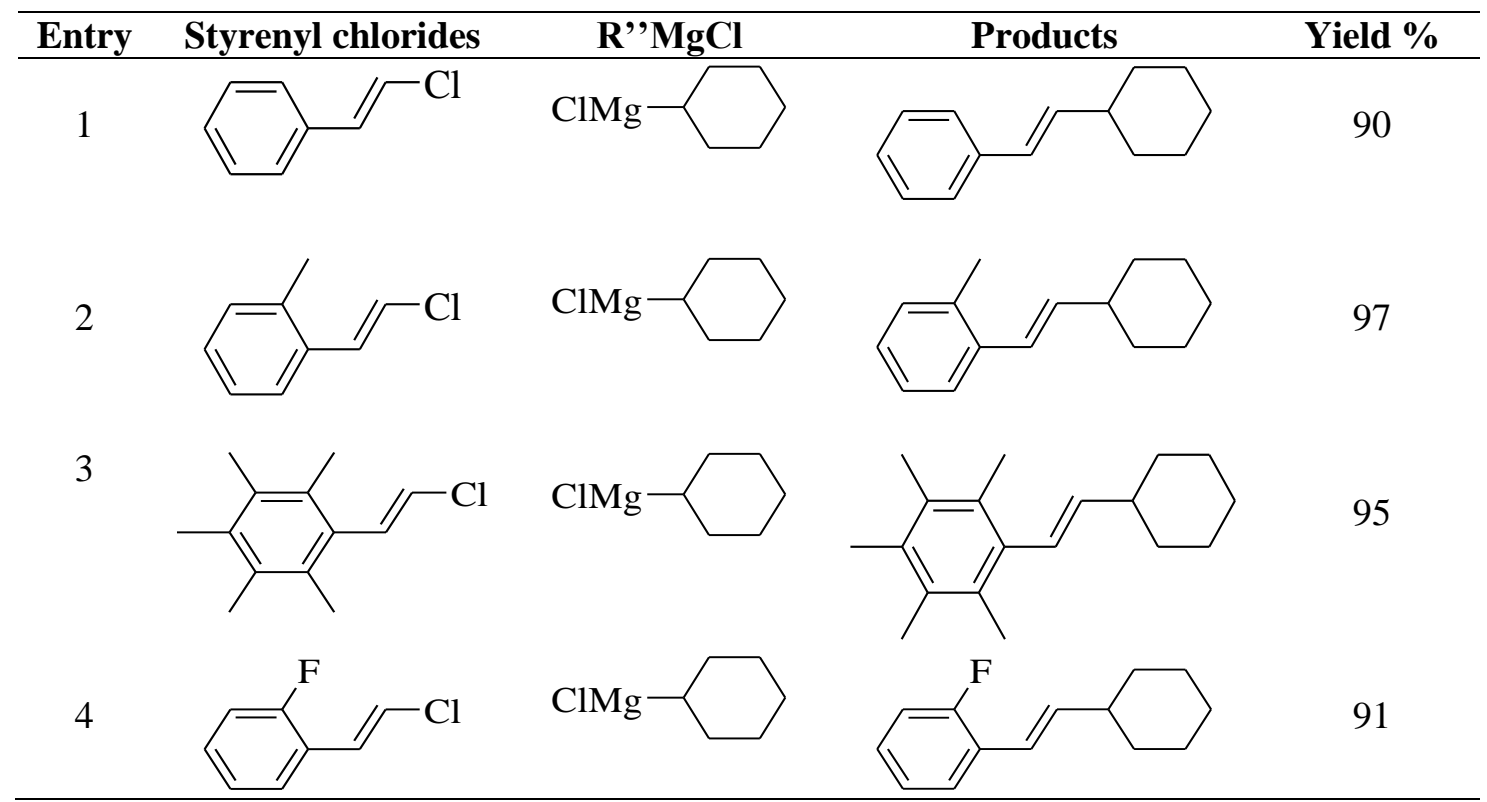

Szostak and Bisz tried out to find a simple and appropriate ligand system to replace NMP (Nmethyl-2-pyrrolidone), which is a common additive in many iron cross coupling reactions. As known, NMP is an environmentally hazardous compound and has health risks and would be unreasonable for industrial and pharmaceutical applications. Thus, they designed an efficient protocol for coupling arylchlorobenzoates 66 with alkylmagnesium halides 67 using Fe(acac) $)_{3}$ with DMI (DMI = 1,3-dimethyl2 -imidazolidinone) as a catalyst system at $0{ }^{\circ} \mathrm{C}$ to obtain the corresponding coupled products 68 in good yields (Table 16, entries $1-5)^{55}$. Consequently, utilizing one of the urea ligands such as DMI improved efficiency of the coupling reaction compared to the conventional additive NMP. However, it was found that sterically bulky and withdrawing groups are not well tolerated. Noteworthy, Szostak and Bisz considerably extended the scope of urea ligands as benign effective additives such as DMPU (DMPU=1,3dimethyl-3,4,5,6-tetrahydro-2(1H)-pyrimidinone), TMU (TMU $=1,1,3,3$-tetramethylurea), $\mathrm{N}$ methylcaprolactam, N,N-bis(2-methoxyethyl)benzamide and phenyl(piperidin-1-yl)methanone, which is an ideal alternative to the hazardous NMP in coupling reactions.

Table 16. Iron-catalyzed $\mathrm{C}\left(\mathrm{sp}^{2}\right)-\mathrm{C}\left(\mathrm{sp}^{3}\right)$ cross-coupling of aryl chlorobenzoates with alkylmagnesium reagents 
<smiles>[R][R]c1cccc(OC(=O)c2ccc([R])cc2)c1</smiles>

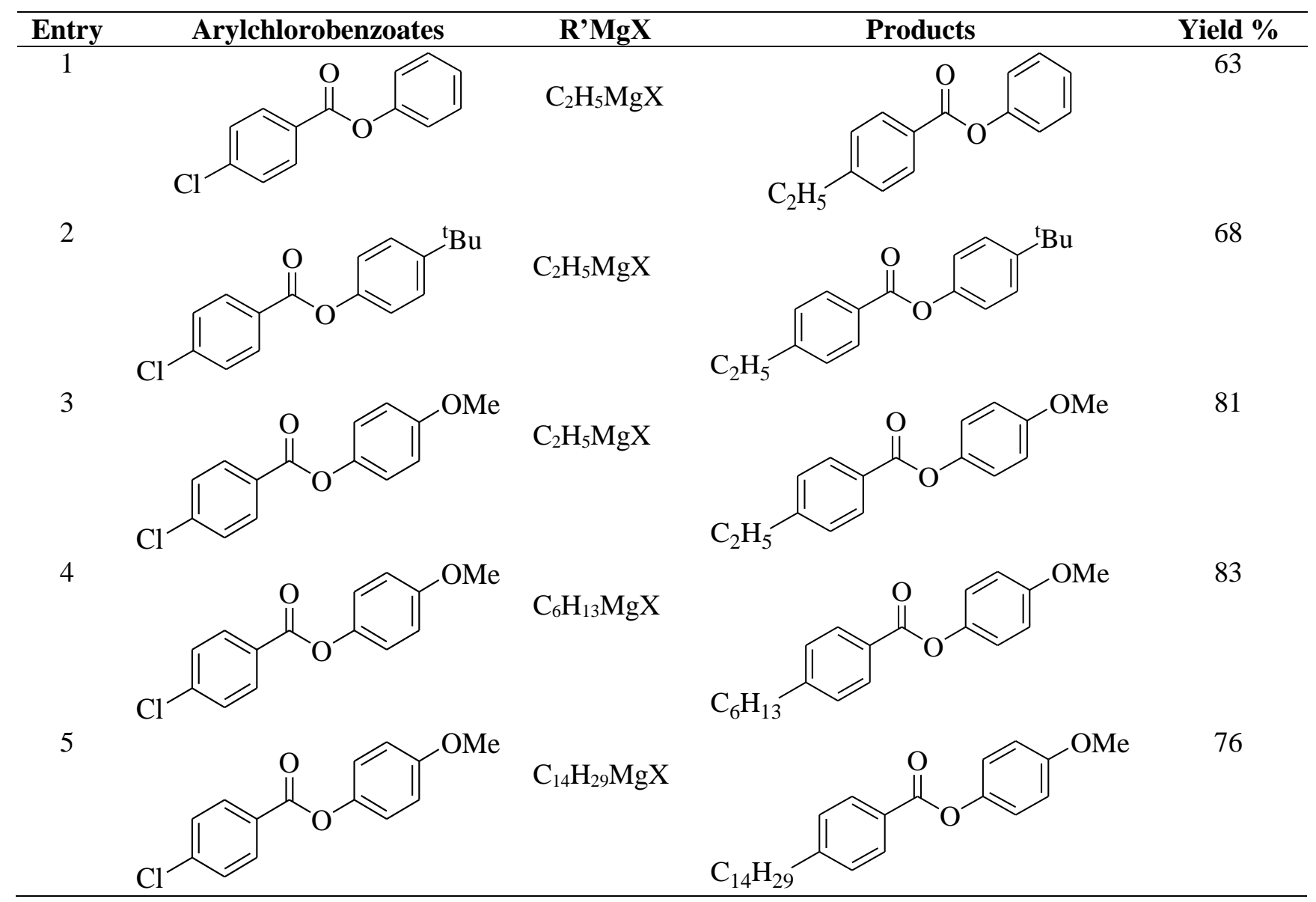

\subsection{Iron Catalyzed Cross-coupling of Phenyl/ Arylmagnesium Reagents}

Bis(2-bromovinyl)benzenes derivatives $\mathbf{7 1}$ play a crucial role in the preparation of conjugated (parylenevinylene) polymers with interesting optical and electronic properties. In 2009, Farinola et al. reported coupling of arylmagnesium reagents $(69 a-69 c)$ and bis(2-bromovinyl)benzenes 70 by using tris(acetylacetonato) iron(III) $\mathrm{Fe}(\mathrm{acac})_{3}$ as an effective catalyst at room temperature to produce the corresponding coupled products in good yields (Scheme 7$)^{56}$. Generally, iron-catalyzed cross-coupling reactions of organomagnesium reagents as nucleophiles are carried out under an inert atmosphere to inhibit deactivation of the catalyst and formation of byproducts, such as homocoupling of the nucleophile. It is worth noting that among complexes of iron, $\mathrm{Fe}(\mathrm{acac})_{3}$ was the appropriate choice for this coupling reaction due to its relatively low cost, air stability, highly catalytic activity, and solubility in ethereal solvents. As observed, the catalyst loading has an influential effect on the efficiency of the coupling reaction; higher catalyst loading improves substantially the yield of the coupling reaction. The optimized coupling protocol has been successfully applied to aryl and heteroarylmagnesium reagents and different divinylbenzene substrates with the aid of $\mathrm{Fe}(\mathrm{acac})_{3}$ catalyst. 
<smiles></smiles>

Scheme 7. Iron catalyzed cross-coupling reaction leading to bis(2-arylvinyl)benzenes

In 2011, Yamaguchi, Asami, and co-workers designed a novel catalyst system for a fast and efficient cross-coupling reaction of arylmagnesium reagents $\mathbf{7 2}$ with cyclohexyl bromide $\mathbf{7 3}$ using iron in combination with a tridentate $\beta$-aminoketone ligand under mild reaction conditions to give the desired products $\mathbf{7 4}$ in satisfactory yields ${ }^{57}$. The nature of the tridentate $\beta$-aminoketone ligand with bulky substituents on nitrogen atoms instead of oxygen atoms in $\beta$-diketonato has an effect on the stabilization of coordinatively unsaturated metal complexes. However, para-substituted arylmagnesium bromides, such as 4-methyl, 4-methoxy, and 4-fluorophenylmagnesium exhibited a high reactivity. Hence the corresponding coupled products were obtained in excellent yields (Table 17, entries, 1, 2, and 4), whilst the reaction of ortho-methoxymagnesium bromide was the lowest because of the steric hindrance. The required products were formed in 33\% yield within 1 hour (entry 3). On the other hand, some coupling reactions gave unexpected byproducts. (Bromomethyl)cyclopropane reacted with phenylmagnesium bromide to give the ring-opened product 4-phenyl-1-butene in $63 \%$ yield, while the corresponding coupled product benzylcyclopropane formed as a minor product (4\% yield). The reaction of 6-bromo-1hexene with phenylmagnesium constructed the ring-closed product benzylcyclopentane in about $23 \%$ yield and along with the simple coupled product 6-phenyl-1-hexene in 34\% yield.

Table 17. The reaction of various arylmagnesium bromides with cyclohexyl bromide catalyzed by iron

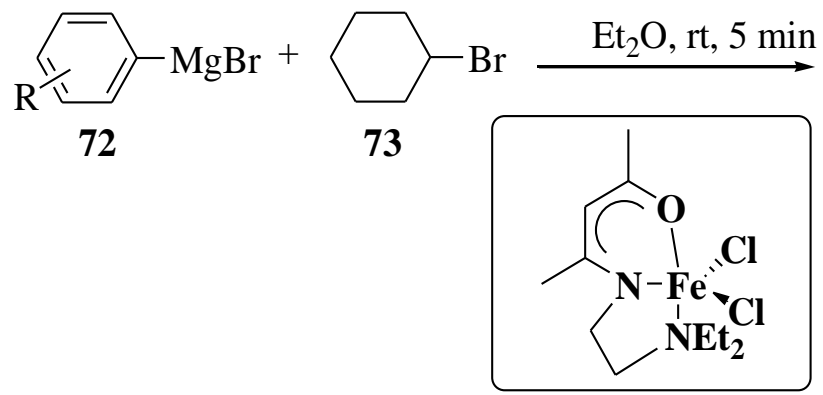

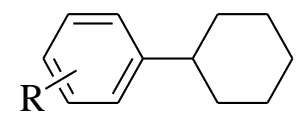

74

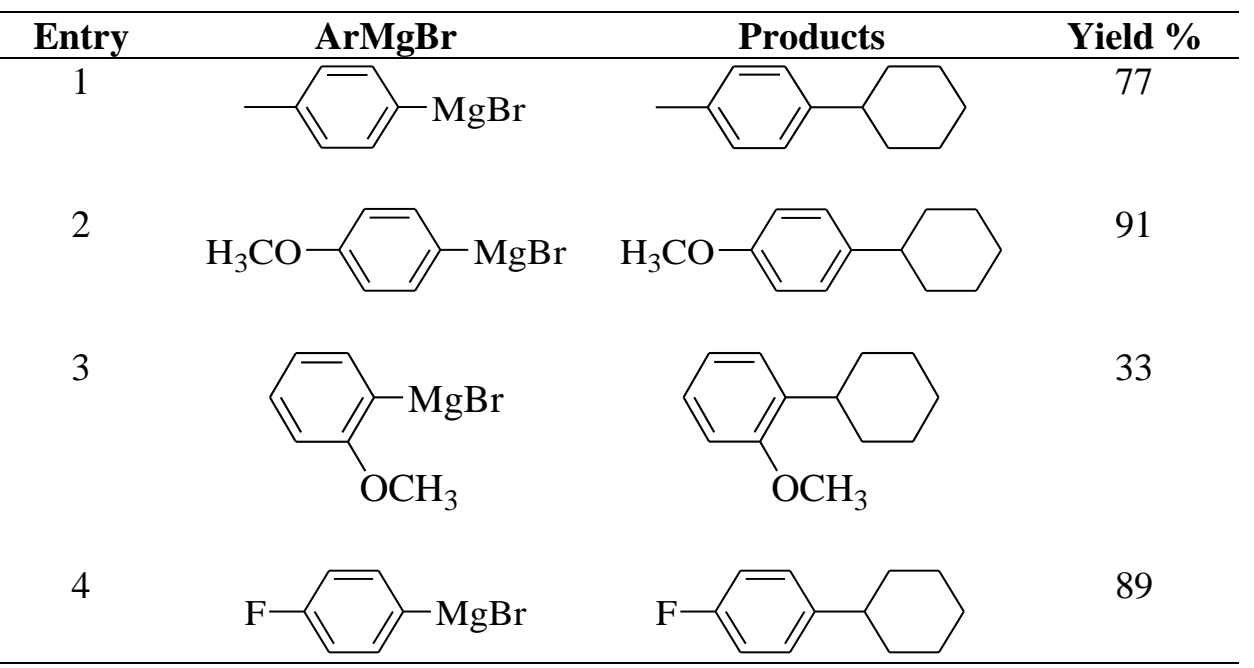


In 2011, Nakamura et al. designed highly efficient iron catalyzed cross-coupling of nonactivated primary and secondary alkyl halides $\mathbf{7 5}$ with arylmagnesium halides $\mathbf{7 6}$ in the presence of 0.5-3.0 mol\% of iron(II)chloride complex possessing a sterically demanding ortho-phenylene-tethered bisphosphine ligand (SciOPPs) to afford acceptable yields of the cross-coupled products $\mathbf{7 7 ^ { 5 8 }}$. Based on the optimized reaction conditions, some cross-coupling reactions proceeded efficiently upon slow addition of the arylmagnesium halides at $40{ }^{\circ} \mathrm{C}$ in $3 \mathrm{~h}$. Accordingly, coupling of cycloheptylbromide with phenylmagnesium bromide in the presence of $\mathrm{FeCl}_{2}\left(3,5-t-\mathrm{Bu}_{2}-\mathrm{SciOPP}\right)$ with a perfect catalytic activity led to high yield of cycloheptylbenzene (Table 18, entry 1). In spite of the relatively prolonged reaction time, cyclohexyl chloride reacted efficiently with phenylmagnesium bromide furnishing the desired product in $82 \%$ yield (entry 2). Interestingly, the reaction was not sensitive to steric hindrance and tolerated some functional groups like, methyl, flouro and methoxy (entries 3, 4, and 5). Moreover, under the same reaction conditions, a ring opening product was considerably observed in this coupling reaction, where (iodomethyl)cyclopropane reacted with mesitylmagnesium bromide to give exclusively 2-(2-buten1-yl)-1,3,5-trimethylbenzene in the absence of the formation of the desired coupled product.

Table 18. Cross-coupling reaction of primary and secondary alkyl chlorides with arylmagnesium halides in the presence of $\mathrm{FeCl}_{2}\left(3,5-t-\mathrm{Bu}_{2}-\mathrm{SciOPP}\right)$

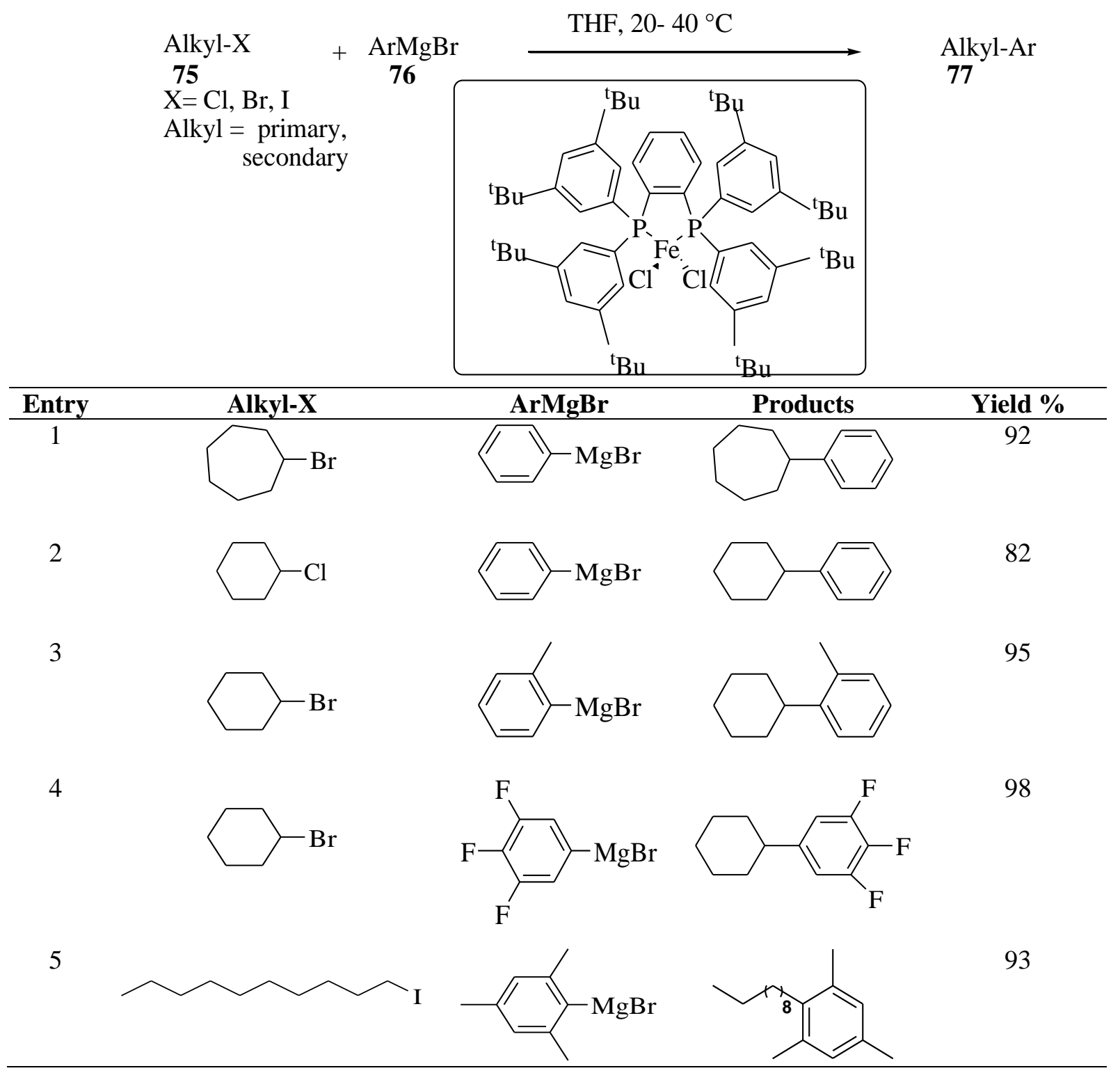


As is well known, nonactivated alkyl fluorides are challenging substrates for metal catalyzed cross-coupling reactions, as they are reluctant to undergo oxidative addition. Additionally, metal alkyl intermediates are prone to induce unproductive $\beta$-hydride eliminations. In 2012, Deng and co-workers developed optimal conditions, using a low-coordinate dinuclear iron complex as a powerful catalyst to carry out successfully cross-coupling of nonactivated primary alkyl fluorides $\mathbf{7 8}$ with arylmagnesium bromides 79 to provide the coupled products in high yields ${ }^{59}$. Thereby, they investigated the influence of arene substituents of arylmagnesium bromides on the efficiency of the coupling reaction through $\left(\mathrm{IPr}_{2} \mathrm{Me}_{2}\right) \mathrm{Fe}\left(\mu_{2}-\mathrm{NDipp}\right)_{2} \mathrm{Fe}\left(\mathrm{IPr}_{2} \mathrm{Me}_{2}\right)$ catalyzed coupling reaction of n-octyl fluoride with variety of arylmagnesium bromides at room temperature or at $60{ }^{\circ} \mathrm{C}$. Arylmagnesium bromides, irrespective of electron-donating or electron-withdrawing substituents, underwent cross-coupling efficiently under the optimized reaction conditions to generate acceptable yields of the corresponding products 80, with the formation of much lower amount of the byproducts such as n-octane and octenes (Table 19, entries 1-7). Likewise, in this coupling protocol, reaction of cyclopropylmethylene fluoride with $p-\mathrm{Me}-\mathrm{C}_{6} \mathrm{H}_{4} \mathrm{MgBr}$ afforded not only the ring-opening product 4-methyl-1-(3'-butenyl)benzene but also the cyclopropyl derivative 4-methyl-1-cyclopropylmethylbenzene, in addition to 4,4'-dimethylbiphenyl. Undoubtedly, the occurrence of ring opening products is still a central challenge in sustainable iron catalysis of coupling of the (iodomethyl)cyclopropane analogue substrates and this challenge needs to be addressed to make these reactions more synthetically valuable.

Table 19. Iron-catalyzed arylation of n-octyl fluoride with arylmagnesium bromides

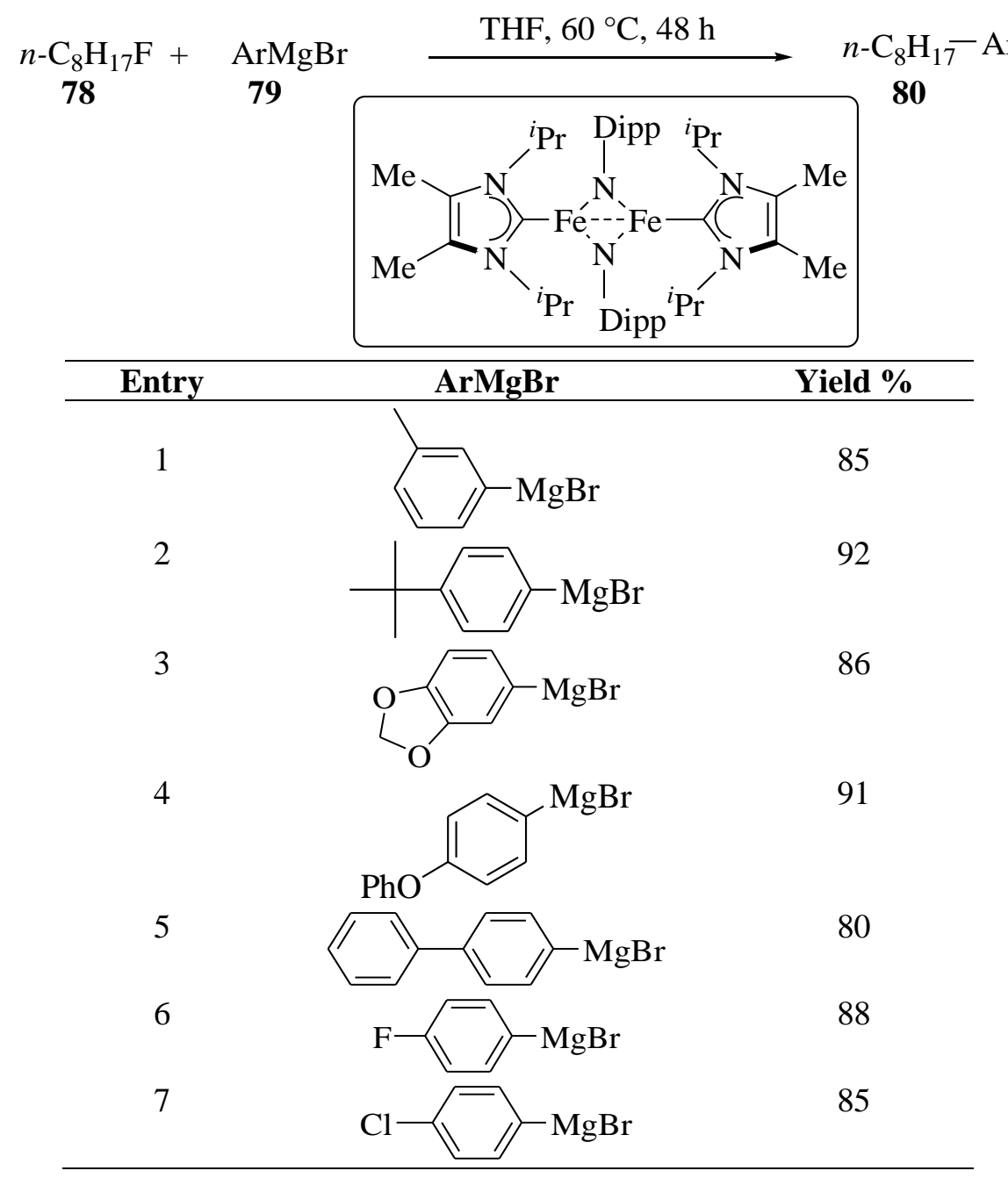

In 2012, Knochel demonstrated an efficient coupling of $\mathrm{N}$-heterocyclic chlorides $\mathbf{8 1}$ and bromides with arylmagnesium halides having a lithium-chloride adduct 82, catalyzed by $\mathrm{FeBr}_{3}$ in $\mathrm{THF} / \mathrm{tBuOMe}$ with the help of an ethereal cosolvent, such as diethyl ether or tert-butyl methyl ether, which was reported 
to be essential to hamper homocoupling side reactions ${ }^{60}$. Under this optimized coupling methodology, formation of a broad spectrum of functionalized $\mathrm{N}$-heterocyclic products resulted in satisfactory yields (Table 20, entries 1-6). Additionally, in all cases, this optimized cross-coupling protocol tolerated a broad range of functional groups including electron-withdrawing groups, such as trifluoromethyl, fluoro, and pivalate functions, as well as electron-donating groups, such as methoxy and dimethylamino. Although, this work aimed at improving practical aspects of iron-catalyzed cross-coupling, we think, this type of $\mathrm{Csp}^{2}-\mathrm{Csp}^{2}$ coupling is particularly limited to halo pyridine and quinoline substrates. Therefore, it requirs to expanded the scope of the substrate to include more $\mathrm{N}$ - heterocyclic compounds.

Table 20. Iron-catalyzed cross-couplings of N-heteroarylchlorides/-bromides with various arylmagnesium halides with a lithium-chloride adduct
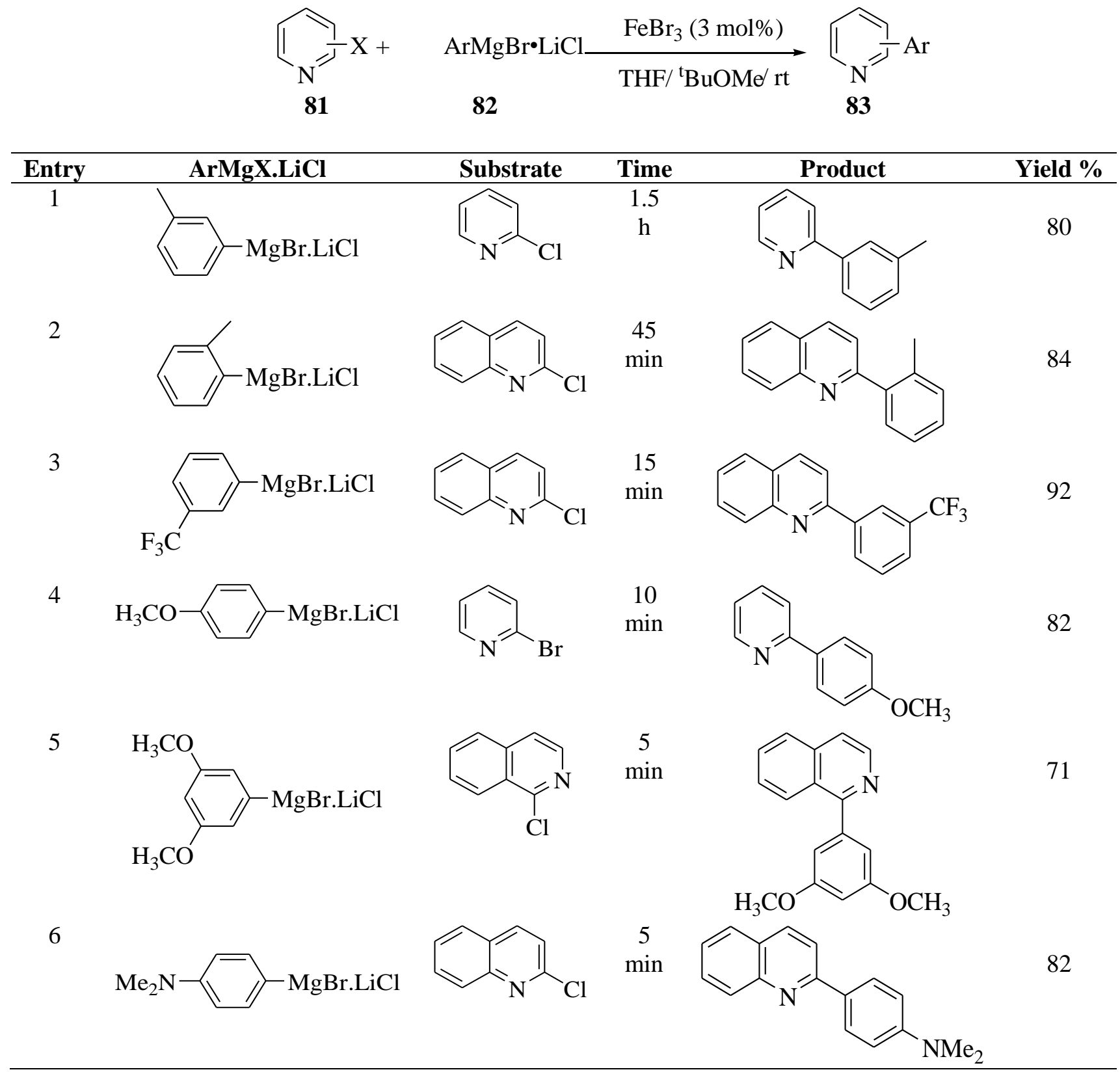

In 2013, Knochel and coworkers showed that functionalized heteroaryl halides $\mathbf{8 4}$ could be used for coupling reaction with arylmagnesium halides $\mathbf{8 5}$ in the presence of catalytic amount of iron(III) bromide (3 mol\%), tert-butyl methyl ether-tetrahydrofuran and $10 \mathrm{~mol} \%$ of quinoline or isoquinoline as a catalyst system at mild reaction conditions to generate the expected cross-coupling products $\mathbf{8 6}$ having 
a variety of chloro- or bromo-substituted pyridines ${ }^{61}$. Remarkable, isoquinoline (and quinoline) clearly played an essential role in the acceleration of the coupling of N-heteroaromatic halide substrates with arylmagnesium halide nucleophiles via ligation to the iron tribromide salt, and to minimize side products. In this optimized cross-coupling methodology, the coupling reaction was compatible with arylmagnesium halides bearing broad scope of sensitive functional groups to afford the corresponding products in good yields (Table 21, entries, 1-3). In addition, pyrimidine derivatives formed from the same set of arylmagnesium halides to afford functionalized N-heterocycles in good yields (entries 4-5). Chlorotriazines reacted smoothly with arylmagnesium reagents to give the desired products in synthetically useful yields (entries 6-7).

Table 21. Scope of Fe-catalyzed cross-coupling reactions utilizing isoquinoline as a ligand

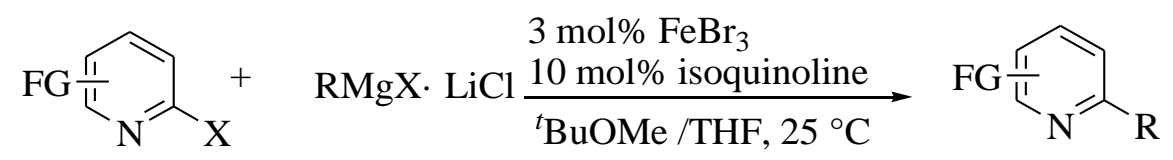

84

$85 \quad 15 \mathrm{~min}$

86<smiles></smiles> 
Table 21. continued..

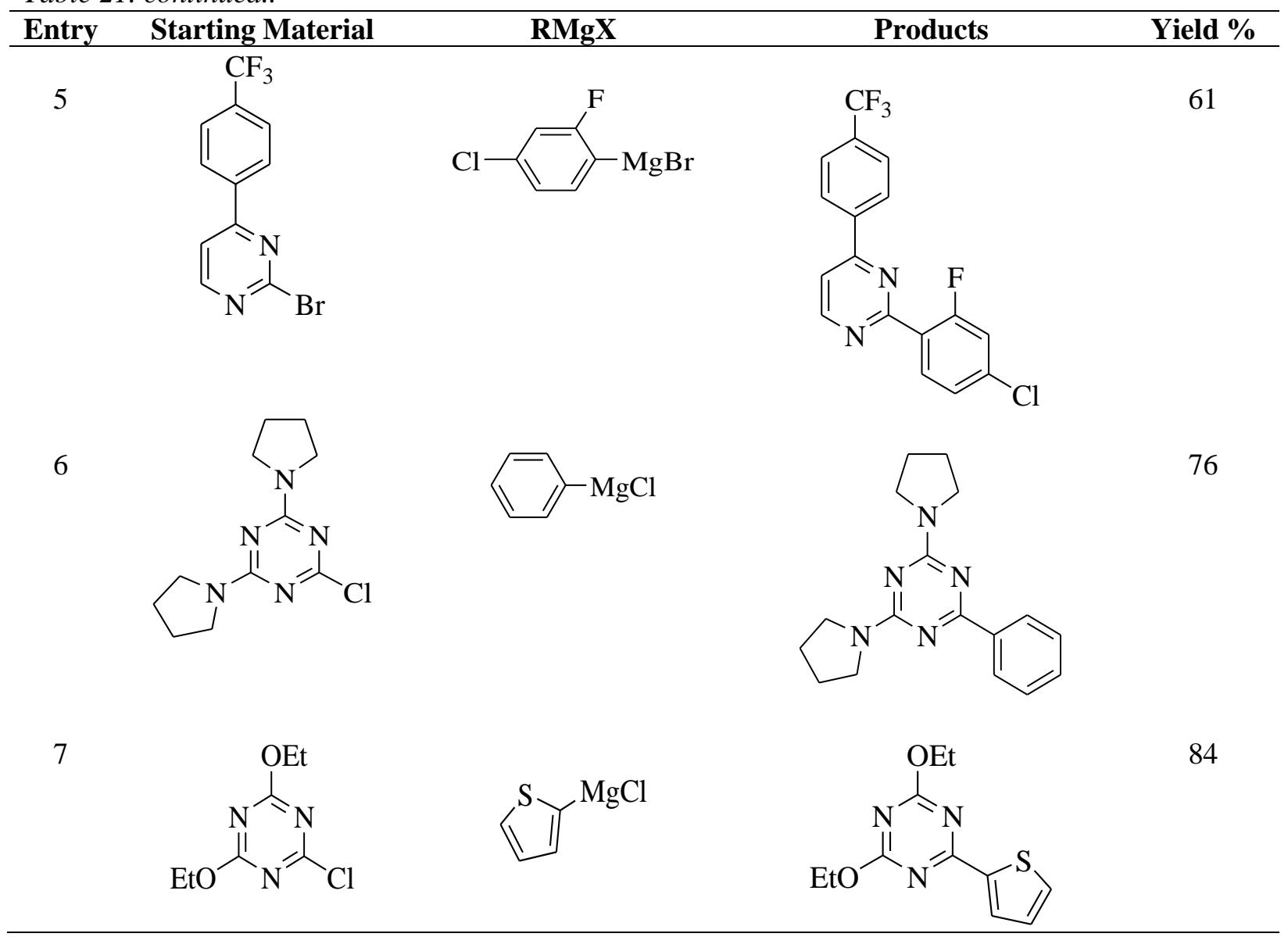

The performance of iron-catalyzed aryl-alkyl cross-couplings between benzylic chloride substrates and arylmagnesium bromide reagents was often a complicated task due to the formation of considerable amount of homocoupling side products of the benzylic chlorides 90. In 2013, Nakamura and coworkers made a distinct contribution to the development of a coupling reaction of benzylic chlorides $\mathbf{8 8}$ and substituted arylmagnesium bromide reagents $\mathbf{8 7}$ through iron-bonded electronically tuned orthophenylenebisphosphine ligands (SciOPPs) as promising catalysts to afford the coupled products $\mathbf{8 9}$ in acceptable yields ${ }^{62}$. Building upon this protocol, arylmagnesium bromide with electron donating groups such as methoxy, methyl and phenyl furnished the coupled products in good yield (Table 22, entries, 1-4). In contrast, the more electron deficient 3-, 4-, 5-trifluorophenyl magnesium bromides did not afford the desired product at all (entry 5). Whereas, the sterically hindered 2-methylbenzyl chloride underwent coupling reaction with phenylmagnesium bromide to provide the desired product with only $13 \%$ yield and the biaryl homocoupling product in 52\% yield (entry 6). Nonetheless, as mentioned earlier, under the same catalyst system, utilizing nonactivated primary and secondary alkyl halide substrates to couple with arylmagnesium nucleophiles (Table 18) showed higher efficiency than the benzylic chloride substrates. Employment of more electron deficient 3-, 4-, 5- trifluorophenyl magnesium bromide afforded the coupled product in $98 \%$ yield.

In 2015, Nakamura et al. successfully achieved the first enantioselective coupling reaction between an organometallic nucleophile and an organic electrophile using iron catalyst to generate optically active fine chemicals ${ }^{63}$. Enantioselective coupling reaction of racemic $\alpha$-chloroalkanoates 91 with arylmagnesium reagents 92 by employing stoichiometric amount of $\mathrm{Fe}(\mathrm{acac})_{3}$ with chiral ligand (R, R)-(+)-1, 2-bis(di-t-butylmethylphosphino)benzene as an efficient catalyst produced optically active $\alpha$ arylalkanoates 93 in synthetically useful yields with higher enantiomeric ratio (er) (Table 23, entries 1-6). 
Table 22. Coupling reaction of benzylic chlorides and substituted arylmagnesium reagents

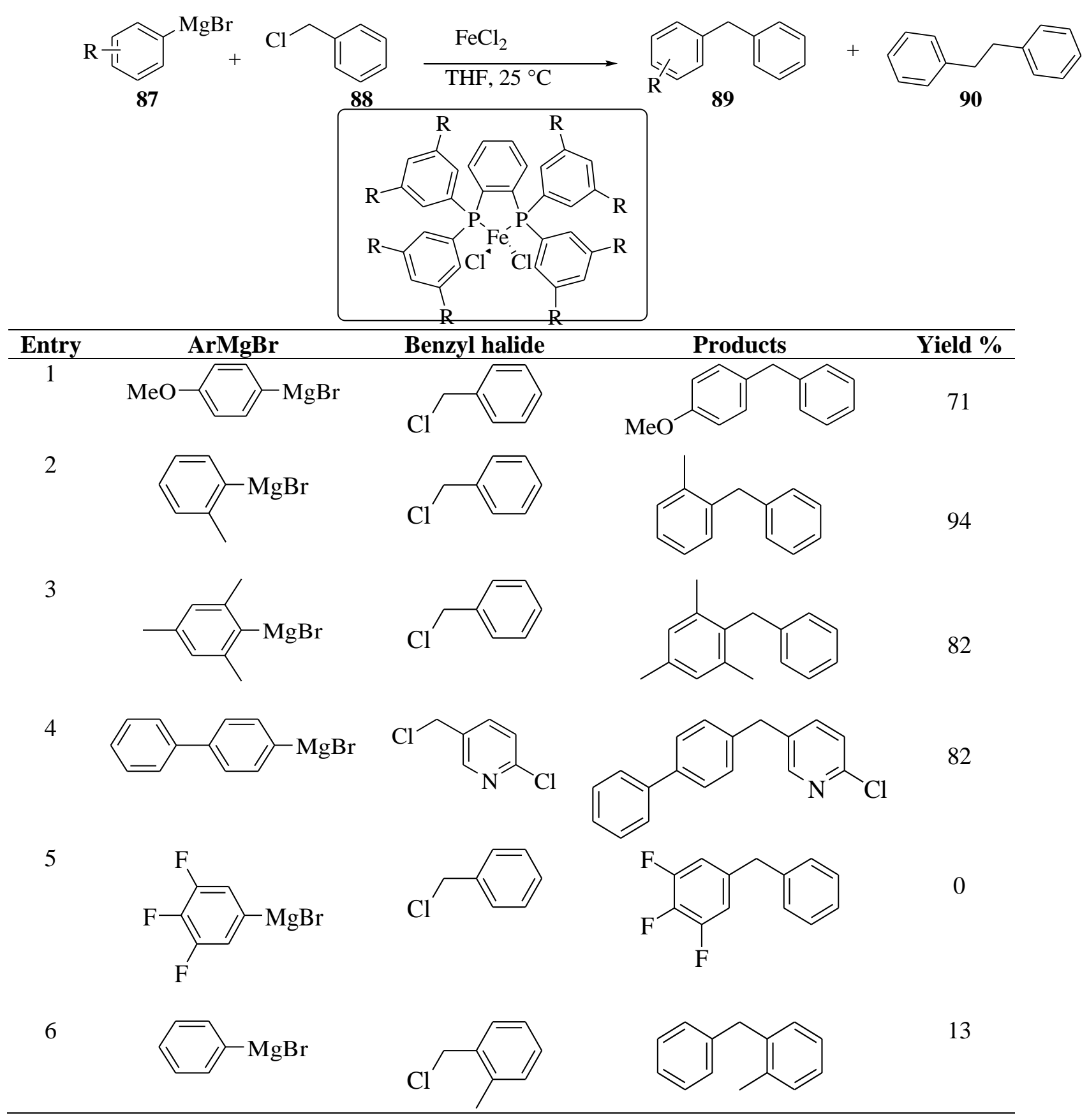

It is worth noting that arylmagnesium reagent was slowly added to the racemic mixture by a syringe pump. This cross-coupling protocol tolerates a broad range of functional groups. This significant coupling reaction remains limited to $\alpha$-chloro ester substrates. Moreover, employment of P-chiral bisphosphine ligands appears crucial to the success of the reaction. 
Table 23. Scope of iron-catalyzed enantioselective coupling of $\alpha$-chloroalkanoate<smiles>[R]OC(=O)C([R])Cl</smiles>

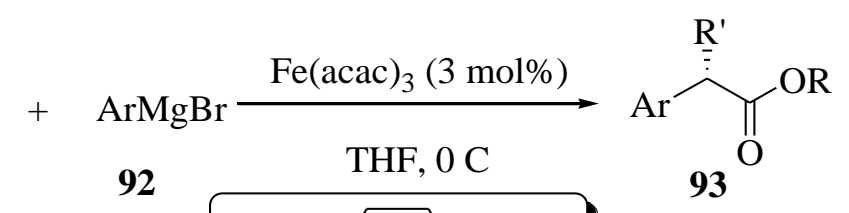

racemic mixture

$\mathrm{R}^{\prime}=\mathrm{Me}, \mathrm{Et}, \mathrm{Bu}, \mathrm{MeOCH}_{2}$ $\mathrm{R}=\mathrm{CH}_{2} \mathrm{CH}\left(\mathrm{CH}_{3}\right)_{2} \mathrm{C}\left(\mathrm{CH}_{3}\right)_{3}$

Entry

In 2015, Hu et al. developed a coupling reaction of alkyl halides 94 with phenylmagnesium chloride reagents 95 through iron-bonded pincer ligands as powerful catalysts to afford the corresponding coupled products in moderate to excellent yields ${ }^{64}$. Thus, tridentate chelating pincer ligands have an important role in influencing stabilization of the catalytically active iron centers. A unique $\mathrm{Fe}$ bis(oxazolinylphenyl)amido catalytic complex permits the alkyl-phenyl bond formations which were successfully achieved via coupling of nonactivated primary and secondary alkyl halides with phenylmagnesium reagents at room temperature (Table 24, entries, 1-5). This coupling reaction proceeded smoothly without any additives and showed excellent functional group tolerance. In this way, even natural-product-derived compounds, such as 3-iodocholestene, were efficiently coupled with phenylmagnesium chloride in moderate to good yields (entry, 6). 
Table 24. Cross-coupling reaction of alkyl halides with phenylmagnesium reagents

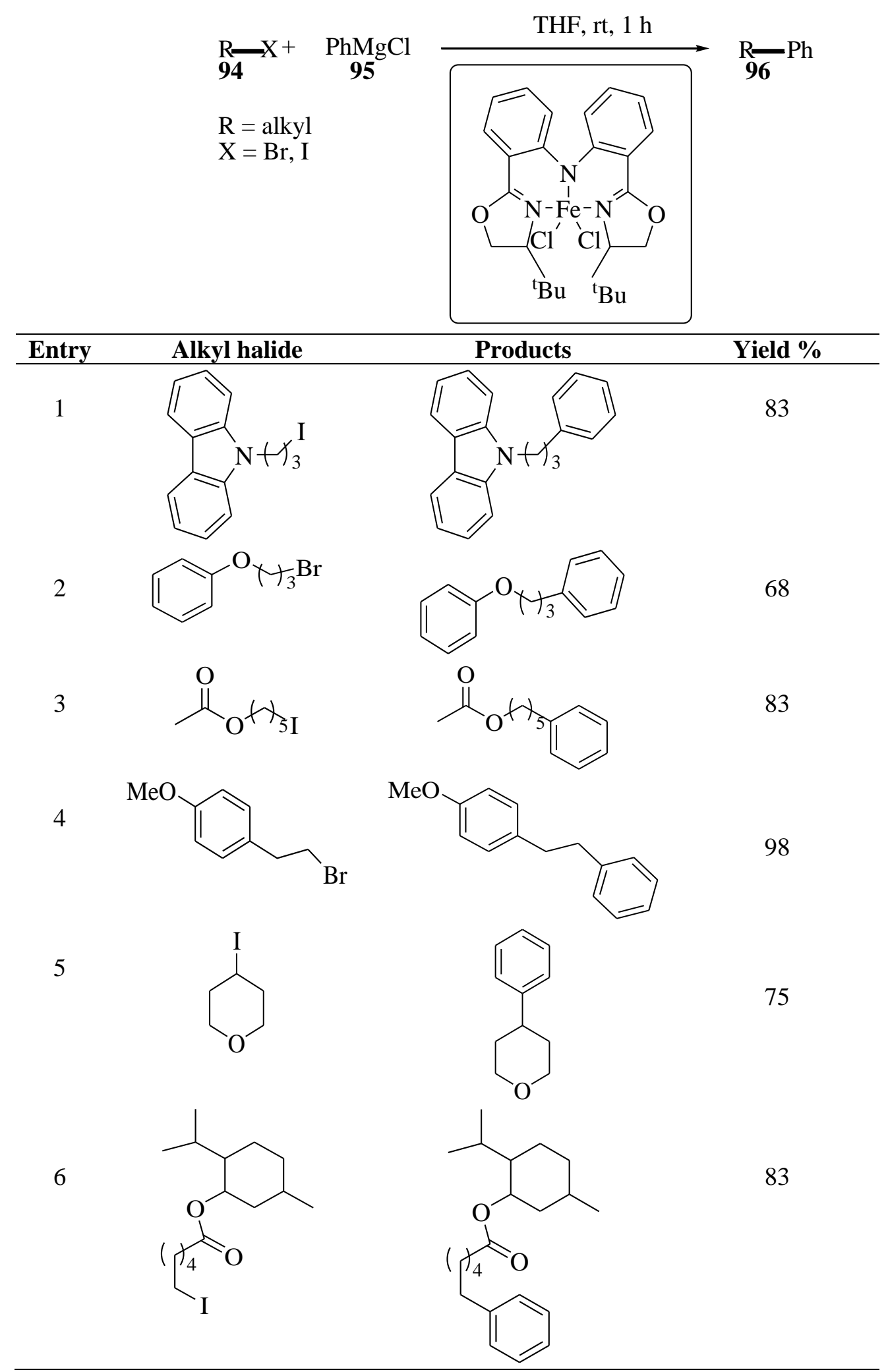


Active allylic compounds bearing halides, acetates, carbonates, etc. as leaving groups were proved to be very promising electrophilic substrates for catalyzed cross-coupling reactions due to their widespread existence and use. In 2016, Zhiping Li et.al performed a seminal research on the ironcatalyzed coupling reactions for $\mathrm{C}-\mathrm{C}$ bond formation using allylic ethers $\mathbf{9 7}$ and phenylmagnesium bromides 98 as a nucleophilic partner ${ }^{65}$. Consequently, various allylic ether substrates with phenoxy group as a leaving group was efficiently coupled with phenylmagnesium bromide catalyzed by $\mathrm{Fe}(\mathrm{acac})_{3}$ in the presence of NMP at $-15{ }^{\circ} \mathrm{C}$ to generate a diverse array of the corresponding coupled products in good to excellent yields (Scheme 8, 99a-99e). It should be noted that there was no reaction in the presence of the other iron catalysts such as $\mathrm{FeCl}_{2}$ and $\mathrm{FeCl}_{3}$. Furthermore, NMP was an essential to achieve high yield of the coupled products. Phenoxy group with electron-donating groups on the phenyl ring was successfully applied as a leaving group in this coupling reaction, while the other O-based leaving groups, such as methoxy and acetate, were not particularly useful for the transformation.<smiles>[R]C=C([R])C([R])Oc1ccc(Br)c(C(F)(F)F)c1</smiles>

97<smiles>COC(=O)c1ccc(C)cc1</smiles>

99a, $99 \%$
98<smiles>Brc1ccc(/C=C/Cc2ccccc2)cc1</smiles><smiles>[R]C=C([R])Pc1ccccc1</smiles>

99<smiles>CC(/C=C/c1ccccc1)c1ccccc1</smiles>

99c, $75 \%$<smiles>C=CCc1ccccc1</smiles>

99d, $83 \%$<smiles>C=C(Cc1ccccc1)c1ccccc1</smiles>

99e, $87 \%$

Scheme 8. Fe(acac) $)_{3}$ catalyzed coupling of various allylic ethers with phenylmagnesium bromide

In 2016, Buono and coworkers developed the first example of continuous flow of $\mathrm{Fe}(\mathrm{acac})_{3}$ catalyzed cross-coupling of 2-chloropyrazine $\mathbf{1 0 0}$ and various para-substituted arylmagnesium reagents 101 in the presence of low catalyst loadings $(0.5 \mathrm{~mol} \%)$. This methodology resulted in a significant improvement in the yield of the desired products, an increase of the iron catalyst stability, reproducibility and scalability at low catalyst loadings ${ }^{66}$. In addition, precise control of the reaction conditions and prolonged catalyst lifetime were observed. Briefly, continuous flow coupling reaction was carried out via solution of 2-chloropyrazine, $\mathrm{Fe}(\mathrm{acac})_{3}(0.5 \mathrm{~mol} \%)$ in THF $(36 \mathrm{~mL})$ (stream A) and 4fluorophenylmagnesium bromide in THF (1 M) (stream B) were pumped into a jacketed static mixer (5 $\mathrm{mL}$ ) followed by a jacketed tube at $-20^{\circ} \mathrm{C}$. It was then quenched into receiving flask containing methanol at $25{ }^{\circ} \mathrm{C}$. The flow pumps were calibrated to obtain an average of $2 \mathrm{~min}$. of residence time (Flow rate pump-stream A: $5 \mathrm{~mL} / \mathrm{min}$, stream B: $6.5 \mathrm{~mL} / \mathrm{min}$, total flow rate $11.5 \mathrm{~mL} / \mathrm{min}$ ). The stream lines are precooled to $-20{ }^{\circ} \mathrm{C}$ before mixing. After the solvent was removed, a saturated solution of $\mathrm{NH}_{4} \mathrm{Cl}$ was added and the product was extracted with EtOAc. The organic phase was separated and dried with $\mathrm{Na}_{2} \mathrm{SO}_{4}$. Purification by flash chromatography gave the product $\mathbf{1 0 2}$ as a white solid ( $82 \%$ yield) (Scheme 9, 102102d).<smiles></smiles>

100<smiles></smiles>

101

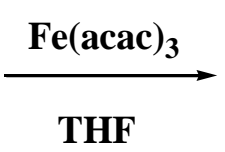

THF<smiles>[R]1ccc(-c2cnccn2)cc1</smiles>

102 
<smiles>c1ccc(-c2cnccn2)cc1</smiles>

102a, $70 \%$<smiles>Cc1ccc(-c2cnccn2)cc1</smiles>

102b, $81 \%$<smiles>Clc1ccc(-c2cnccn2)cc1</smiles>

$102 c, 63 \%$<smiles>COc1ccc(-c2cnccn2)cc1</smiles>

102d, $75 \%$

Scheme 9. Coupling of 2-chloropyrazine with aryl Grignard reagents catalyzed by $\mathrm{Fe}(\mathrm{acac})_{3}(0.5 \mathrm{~mol} \%)$

Biaryl compounds are widely used in many large-scale applications in pharmaceutical, liquid crystal, functional polymer and electronic material industries. Hence, the development of straightforward and selective methods for the preparation of biaryls has attracted much attention in recent years. In 2017, Duong and his group reported iron-catalyzed coupling of aryl tosylates $\mathbf{1 0 3}$ with arylmagnesium reagents $\mathbf{1 0 4}$ with the aid of $n$-heterocyclic carbene ligands to afford the biaryl products $\mathbf{1 0 5}^{67}$. Aryl tosylates with electron donating or withdrawing groups were efficiently coupled with functionalized arylmagnesium reagents using $3 \mathrm{~mol} \%$ of iron(II) trifluoromethanesulfonate $\mathrm{Fe}(\mathrm{OTf})_{2}$ in conjunction with 9 mol\% SIPrNaP. $\mathrm{HCl}$ ligand as an efficient catalyst system at $60{ }^{\circ} \mathrm{C}$, which furnished the coupled products in excellent yields (Scheme 10, 105a-105c). Although $\mathrm{N}$-heterocyclic carbene (NHC) ligands have a significant role in the catalytic formation of $\mathrm{C}-\mathrm{C}$ bonds, they are still costly and limited to specific types of the bulky substrates.

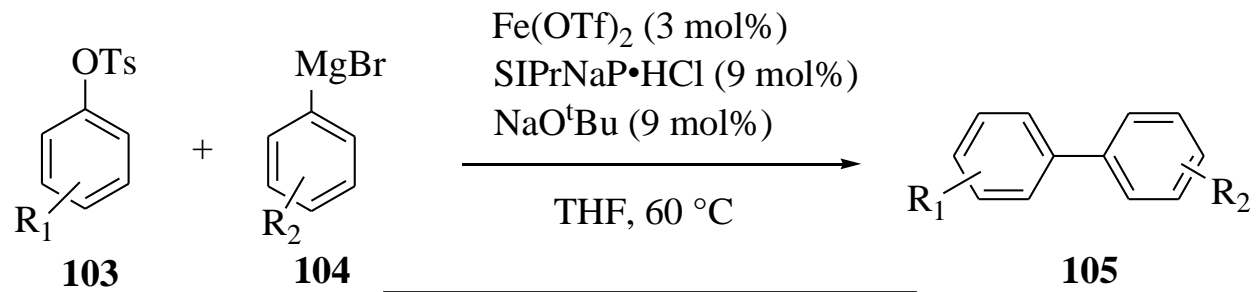

$\mathrm{R}_{1}=\mathrm{F}, \mathrm{OMe}, \mathrm{Me}$

$\mathrm{R}_{2}=\mathrm{F}, \mathrm{OMe}, \mathrm{Me}$

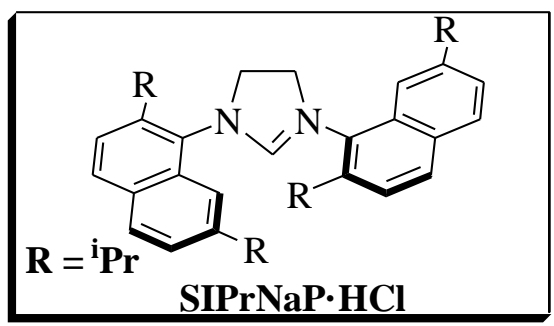

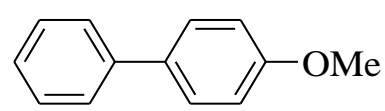

105a, 93\%

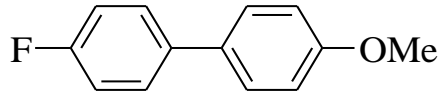

105b, $88 \%$

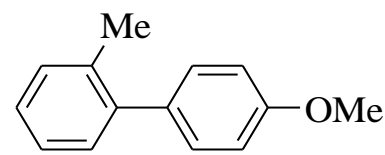

$105 \mathrm{c}, 89 \%$

Scheme 10. Cross-coupling of aryl tosylates and arylmagnesium reagents using $\mathrm{Fe}(\mathrm{OTf}) 2 / \mathrm{SIPrNap} \cdot \mathrm{HCl} / \mathrm{NaOtBu}$

In 2018, Zhang et al. described a novel and powerful methodology for the synthesis of difluoroalkylated arenes to be used in medicinal chemistry and agrochemicals via coupling of arylmagnesium bromides and a wide range of difluoroalkyl bromides catalyzed by iron/bulky diamine catalyst system under mild reaction conditions. Herein, $\mathrm{FeI}_{2} / \mathrm{TMEDA}$ catalyzed efficiently the reaction of various functionalized arylmagnesium bromide nucleophiles 106 with difluoroalkyl bromides 107 at room temperature to synthesize a variety of the corresponding difluoroalkylated arenes 108 with good to high yields (Scheme 11, 108a-108h). Building upon this protocol, the steric effect of TMEDA ligand might play a crucial role in activation of the iron catalyst to promote the catalytic cycle ${ }^{68}$. This coupling methodology is practically useful only via using $\mathrm{FeI}_{2} / \mathrm{TMEDA}$ catalyst system at high loading. Strikingly, when $\mathrm{FeI}_{2}$ was replaced with $\mathrm{FeCl}_{2}$, the coupling products were not observed. 
<smiles>[R]C1=CCC([M])C=C1</smiles>

108a, $90 \%$<smiles>CC(F)(CCCC(F)(F)c1ccc(C(F)(F)F)cc1)c1ccccc1</smiles>

108e, $60 \%$<smiles>CC(F)(CCC(F)(F)c1ccccc1)c1ccccc1</smiles><smiles>[Mg]Br</smiles><smiles>FC(F)([Al+2])Br</smiles>

106

107<smiles>CC(F)(F)Cc1ccc(C(C)(F)CCC(F)(F)c2ccccc2)cc1</smiles>

108b, $60 \%$

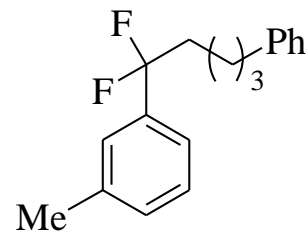

108f, $55 \%$
$\mathrm{FeI}_{2}(10 \mathrm{~mol} \%)$

TMEDA (10 mol\%)

THF/dioxane

rt, $90 \mathrm{~min}$<smiles>FC(F)(CCCCCCC(F)(F)c1ccc(-c2ccccc2)cc1)c1ccccc1</smiles>

108c, $90 \%$

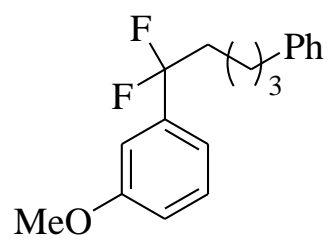

108g, $74 \%$<smiles>FC(F)([AlH2])c1ccccc1</smiles>

108

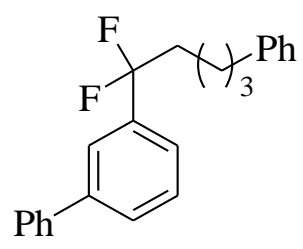

108d, $72 \%$<smiles>FC(F)(CCCCCC(F)(F)c1ccc2ccccc2c1)c1ccccc1</smiles>

108h, $67 \%$

Scheme 11. Fe-catalyzed difluoroalkylations of arylmagnesium bromides with difluoroalkyl bromides

In 2018, Huynh and Duong reported iron-catalyzed cross-coupling reactions of substituted arylmagnesium reagents 110 and aryl chlorides 109 using optimal sterically bulky N-heterocyclic carbenes $(\mathrm{NHCs})^{69}$. They investigated the influence of ring size expanded $\mathrm{N}$-heterocyclic carbenes (NHCs) as ligands on the efficiency of the coupling reaction of arylmagnesium reagents and aryl chlorides, by comparing the catalytic performance of Fe-NHC catalyst systems including various NHCs that differ in ring size (5-8). Accordingly, NHC ligand with seven membered ring was demonstrated to be particularly the best for the catalytic activity property in this coupling reaction. Building upon this protocol, electron rich and electron poor arylmagnesium reagents were reacted efficiently with aryl chlorides furnishing the coupled products in relatively good yields (Table 25, entries 1-3). In turn, coupling reaction of both the sterically hindered $o$-tolylmagnesium bromide with 2-chloroanisole generated very poor yield of biaryl coupling products (entry 4).

In 2020, Duan and workers develop two different coupling methods (A and B) to prepare a variety of $Z$ - and $E$-tri- and tetrasubstituted acrylates through iron-catalyzed stereospecific coupling of $Z$ or Eenol tosylates 112 with arylmagnesium halides $\mathbf{1 1 3}^{70}$. Generally, the protocol (method A) performed stereospecific Z-arylated products when the coupling reaction of $Z$-trisubstituted tosyloxyacrylates was applied using $\mathrm{FeCl}_{3} / \mathrm{SIPr}$ with $\mathrm{Ti}(\mathrm{OEt})_{4} / \mathrm{PhOM}$ as a catalyst system under mild reaction conditions to provide high yields of the desired stereospecifically $Z$-trisubstituted acrylates as a single isomer (Scheme $12, Z-114 a-Z-114 f)$, which are normally subjected to isomerization into thermodynamically stable Eisomers. In contrast, unexpectedly, when utilizing the method B for coupling of $Z$ - trisubstituted tosyloxyacrylates as starting compounds with arylmagnesium reagent, only E-isomer was obtained. On the other hand, the method B was applied to the coupling of E-enol tosylates with arylmagnesium halides in the absence NHC ligand in refluxing THF, which led to the formation of E-trisubstituted acrylates in good yields (Scheme 13, E-114a-E-114f). In this context, the method B gave slightly higher yields of Eisomer products compared to the method A. Sensitive and sterically hindrance groups were perfectly tolerated in these methods with complete stereo fidelity. 
Table 25. Scope of the $\mathrm{Fe}(\mathrm{OTf})_{2} / \mathrm{Mes}$-catalysed cross-coupling reaction of arylmagnesium reagents and aryl chlorides

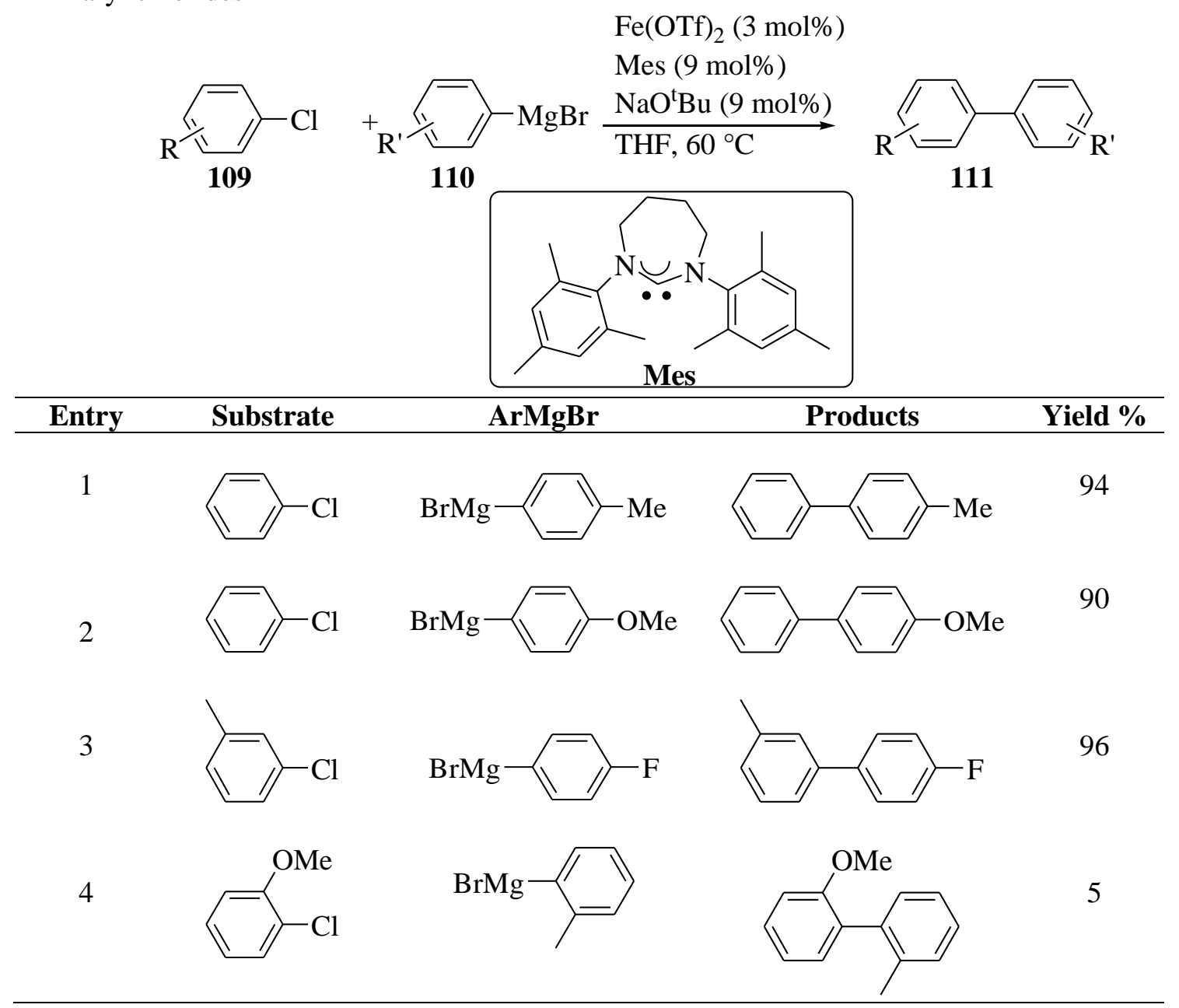

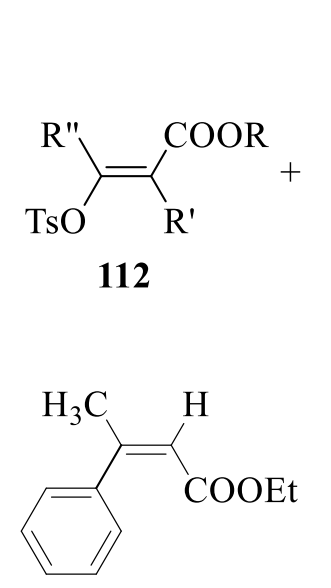

$Z-114 a, 82 \%$

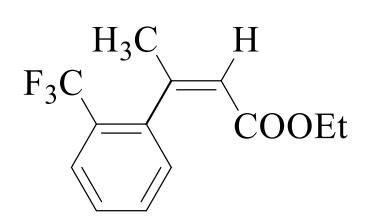

$Z-114 d, 75 \%$
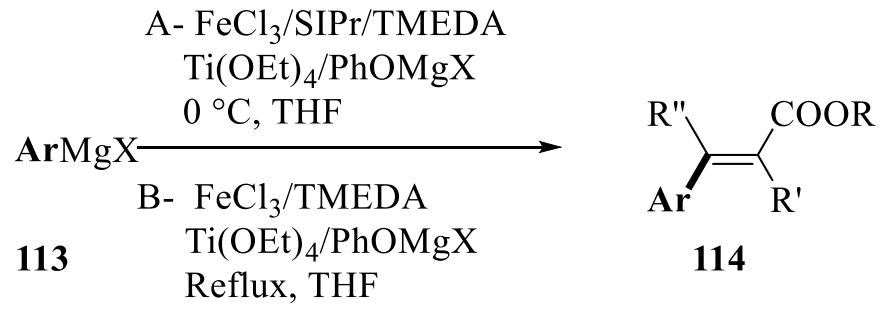

114<smiles>COC(=O)/C=C(/C)c1ccc(C)cc1</smiles><smiles>COC(=O)/C=C(/C)c1ccc(F)cc1</smiles><smiles>CCC/C(=C/C(=O)OC)c1cccnc1</smiles>

$Z-114 \mathrm{e}, 75 \%$<smiles>COC(=O)/C=C(\C)c1cccs1</smiles>

Z-114f, $71 \%$ 
Scheme 12. Z-trisubstituted acrylates using method A

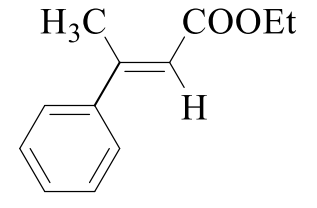

\section{$E$-114a}

Method A : $83 \%$

Method B : $86 \%$

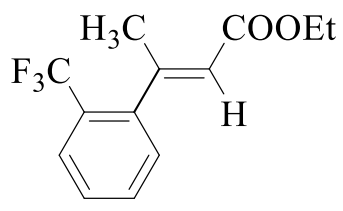

$E$-114d

Method A : $77 \%$

Method B : $82 \%$

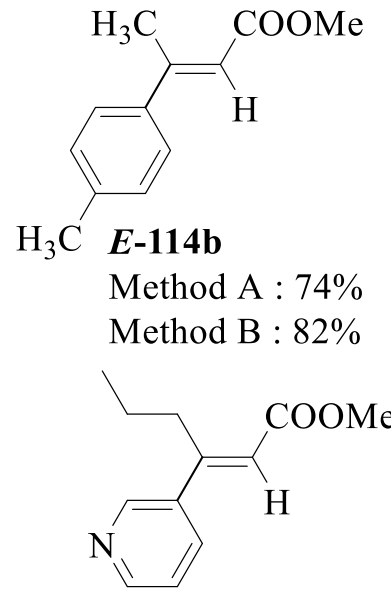

$E$-114e

Method A : 77\%

Method B : $81 \%$<smiles>C/C(=C\c1ccc(C(C)C)cc1)C(=O)O</smiles>

Method A : $75 \%$

Method B : $80 \%$<smiles>COC(=O)/C=C(\C)c1cccs1</smiles>

$E$-114f

Method A : 76\%

Method B : $78 \%$

Scheme 13. E-trisubstituted acrylates using method A and B

\subsection{Iron Catalyzed Cross-coupling Reaction of Alkynylmagnesium Reagents}

Since 2009, few examples of alkynyl-alkyl cross coupling have emerged in the literature. Alkynes are significant building blocks for the chemical synthesis of some complex natural products, and electronic material industries. Hence, Nakamura and coworkers have continued to develop and extend iron-catalyzed cross-coupling reactions to involve a variety of organomagnesium halides with various substrates ${ }^{71}$. They achieved a novel protocol for Sonogashira type coupling of primary and secondary alkyl halides with alkynylmagnesium reagents by using $\mathrm{FeCl}_{2}(\mathrm{SciOPP})$ catalyst to afford the corresponding coupled products in excellent yields over moderately shorter reaction times. However, under the optimized coupling reaction conditions, alkyl halides smoothly underwent coupling reactions with alkynylmagnesium bromide to produce the desired products in good to excellent yields (Table 24, entries 1-3). On the other hand, addition of cyclohexylethynyl magnesium bromide dropwise to a substrate over the longer duration of the reaction time, $20 \%$ catalyst loading of $\mathrm{FeCl}_{2}(\mathrm{SciOPP})$ was required to give the desired product in $64 \%$ yield (entry 4). An impressive demonstration of the chemoselectivity afforded by 1 -bromo-4-chlorobutane, where $\mathrm{C}-\mathrm{Br}$ bond cleavage was favored over $\mathrm{C}--$ $\mathrm{Cl}$ bond cleavage for the cross coupled products through the reaction with the alkynyl magnesium bromide generating the desired products in a synthetically useful yields (entry 5).

Functionalized alkynes are widely used for synthesis of biological active materials. In 2014, Xile $\mathrm{Hu}$ et al. described an effective protocol for the synthesis of versatile substituted alkynes through iron mediated cross-coupling of nonactivated secondary alkyl halide substrates and alkynylmagnesium reagents at room temperature ${ }^{72}$. Consequently, coupling reaction of nonactivated cyclohexyl iodide or 4iodotetrahydropyran 118 with various alkynylmagnesium reagents 119 catalyzed by $\mathrm{FeBr}_{2}$ gave a variety of functionalized alkynes $\mathbf{1 2 0}$ via the formation of unique $\mathrm{C}\left(\mathrm{sp}^{3}\right)-\mathrm{C}(\mathrm{sp})$ bonds in good yields (Scheme 14, 120a-120d). In spite of long reaction time, the coupling reaction was found to be more efficient compared to the iron catalyzed coupling alkynylmagnesium reagents with primary and secondary alkyl halides, developed by Nakamura et al., which also required high temperature and a bisphosphine ligand, bearing peripheral sterically bulky groups, to achieve the reaction (Table 26). 
Table 26. Cross-coupling of alkyl halides with alkynyl magnesium reagents

Alkyl halides $+\quad$ Alkynylmagnesium halides $\stackrel{\mathrm{THF}, 70{ }^{\circ} \mathrm{C}, 2 \mathrm{~h}}{\longrightarrow}$ Alkyl-Alkynyl

115

116

117

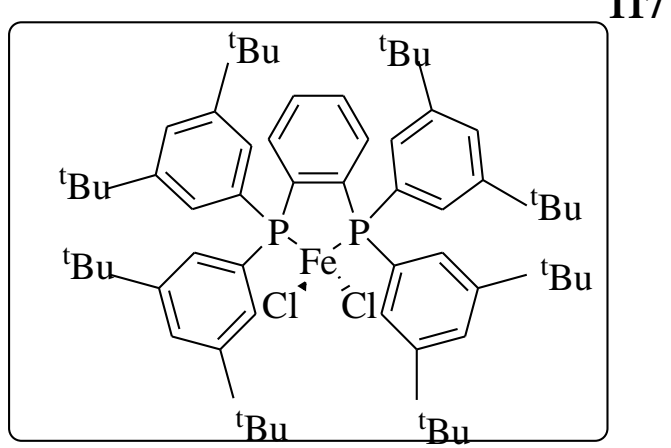

Entry Alkynylmagnesium halide



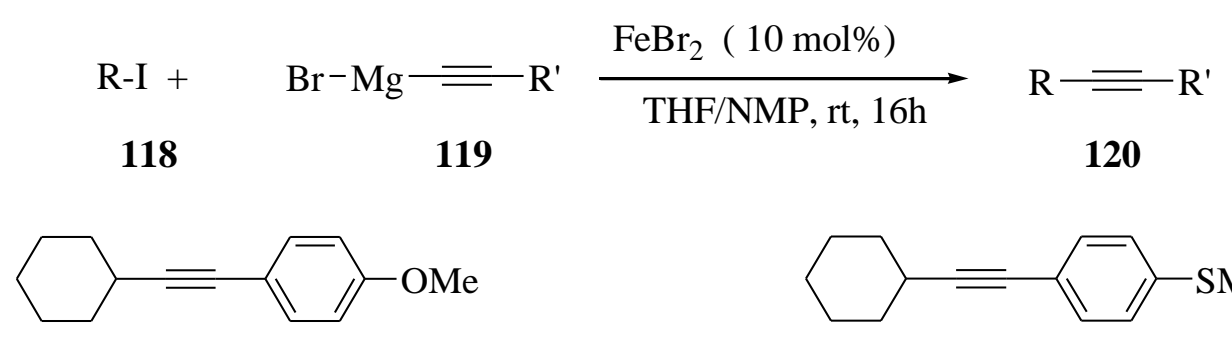

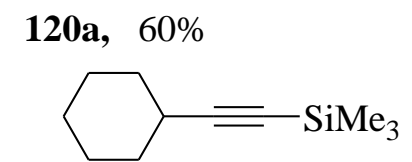

120c, $51 \%$

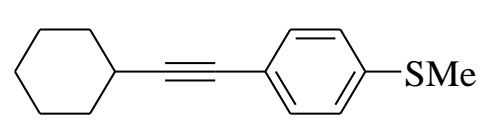

120b, $65 \%$

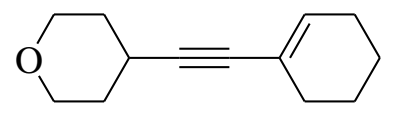

120d, $77 \%$

Scheme 14. Coupling reaction of secondary alkyl halides with alkynyl Grignard reagent using $\mathrm{FeBr}_{2}$

\section{Conclusion}

The use of the abundant and inexpensive transition metals such as iron in developing costeffective synthetic strategies has attracted much attention. Recently, iron complexes containing various ligands have been used as effective catalysts to achieve the coupling reactions of a broad range of substrates and diverse functionalized organomagnesium reagents under appropriate reaction conditions to produce a wide spectrum of significant organic compounds. Organomagnesium reagents play an important role as coupling partners in cross-coupling reactions, owing to their commercially availablity, especially alkylmagnesium and phenyl/ arylmagnesium reagents. This review highlights most crucial recent developments of carbon-carbon bond formation using iron catalyzed cross-coupling reaction of organomagnesium reagent nucleophiles and electrophilic substrates between 2008-2020. We hope this review will serve as a beneficial and simplified introduction for researchers interested in cross-coupling reactions and their applications in pharmaceutical and chemical industries.

\section{Acknowledgements} fellowship.

One of the authors, Mohammed Hassan, is grateful to IIE-SRF, New York, for granting him a

\section{ORCID}

Adnan A. Dahadha: 0000-0002-4160-0622

Mohammad M. Aldhoun: 0000-0003-1768-0738

Mohammed Hassan: 0000-0003-2531-9360

Qutaiba A. Ibrahim: 0000-0002-1165-008X

Nesrin T. Talat: $\underline{0000-0002-9123-6216}$

\section{References}

[1] Jana, R.; Pathak, T. P.; Sigman, M. S. Advances in transition metal (Pd,Ni,Fe)-catalyzed cross- coupling reactions using alkyl-organometallics as reaction partners. Chem. Rev. 2011, 111, 1417-1492.

[2] Terao, J.; Todo, H.; Watanabe, H.; Ikumi, A.; Kambe, N. Nickel-catalyzed cross-coupling reaction of alkyl halides with organozinc and Grignard reagents with 1,3,8,10-tetraenes as additives. Angew. Chem. Int. Ed. 2004, 43, 6180-6182.

[3] Vechorkin, O.; Hu, X. Nickel-catalyzed cross-coupling of non-activated and functionalized alkyl halides with alkyl Grignard reagents. Angew. Chem. Int. Ed. 2009, 48, 2937-2940. 
[4] Miyaura, N.; Yamada, K.; Suzuki, A. A new stereospecific cross-coupling by the palladium-catalyzed reaction of 1-alkenylboranes with 1-alkenyl or 1-alkynyl halides. Tetrahedron Lett. 1979, 20, 3437-3440.

[5] Littke, A. F.; Fu, G. C. Palladium-catalyzed coupling reactions of aryl chlorides. Angew. Chem. Int. Ed. 2002, 41, 4176-4211.

[6] Miyaura, N.; Suzuki, A. Palladium-catalyzed cross-coupling reactions of organoboron compounds. Chem. Rev. 1995, 95, 2457-2483.

[7] Kochi, J. K. Electron-transfer mechanisms for organometallic intermediates in catalytic reactions. Acc. Chem. Res. 1974, 7, 351-360.

[8] Kochi, J. K. Homo coupling, disproportionation and cross coupling of alkyl groups. Role of the transition metal catalyst. J. Organomet Chem. 2002, 653, 11-19.

[9] Tamura, M.; Kochi, J. K. Coupling of Grignard reagents with organic halides. Synthesis 1971, 6, 303-305.

[10] Tamura, M.; Kochi, J. K. Mechanism of the silver-catalyzed reaction of Grignard reagents with alkyl halides. J. Am. Chem. Soc. 1971, 93, 1483-1485.

[11] Tamao, K.; Sumitani, K.; Kumada, M. Selective carbon-carbon bond formation by cross-coupling of Grignard reagents with organic halides. Catalysis by nickel-phosphine complexes. J. Am. Chem. Soc. 1972, 94, 4374-4376.

[12] Tamao, K. Discovery of the cross-coupling reaction between Grignard reagents and $\mathrm{C}(\mathrm{sp} 2)$ halides catalyzed by nickel-phosphine complexes. J. Organomet. Chem. 2002, 653, 23-26.

[13] Murahashi, S. I. Palladium-catalyzed cross-coupling reaction of organic halides with Grignard reagents, organolithium compounds and heteroatom nucleophiles. J. Organomet. Chem. 2002, 653, $27-33$.

[14] Hayashi, T.; Konishi, M.; Kobori, Y.; Kumada, M.; Higuchi, T.; Hirotsu, K. Dichloro[1,1'bis(diphenylphosphino)ferrocene]palladium(II): an effective catalyst for cross-coupling of secondary and primary alkyl Grignard and alkylzinc reagents with organic halides. J. Am. Chem. Soc. 1984, 106, 158-163.

[15] Bolm, C.; Legros, J.; Paih, J. L.; Zani, L. Iron-catalyzed reactions in organic synthesis. Chem. Rev. 2004, 104, 6217-6254.

[16] Alois, F.; Rubén, M. Advances in iron catalyzed cross coupling reactions. Chemistry Letters 2005, 34, 624629.

[17] Dahadha, A, A, Aldhoun, M. M. Nickel and palladium catalyzed Kumada-Tamao-Corriu cross-coupling reactions: scope and recent advances. Arkivoc 2018, (vi), 234-253.

[18] Sherry, B. D.; Furstner, A. The promise and challenge of iron-catalyzed cross coupling. Acc. Chem. Res. 2008, 41, 1500-1511.

[19] Wu, J. R.; Lin, C. H.; Lee, C. F. Iron-catalyzed thioetherification of thiols with aryl iodides. Chem. Comm. 2009, 29, 4450-4452.

[20] Chua, Y. Y.; Hung A. Duong, H. A. Iron(II) triflate/n-heterocyclic carbene-catalysed cross-coupling of arylmagnesiums with aryl chlorides and tosylates. Chem.commun. 2015, 52, 1466-1469.

[21] Piontek, A.; Bisz, E.; Szostak, M. Iron-Catalyzed Cross-Couplings in the Synthesis of Pharmaceuticals: In Pursuit of Sustainability. Angew. Chem. Int. Ed. 2018, 57, 11116-11128.

[22] Campeau, L. C.; Hazari. N. Cross-coupling and related reactions: connecting past success to the development of new reactions for the future. Organometallics 2019, 38, 3-35.

[23] Dongol, K. G.; Koh, H.; Sau, M.; Chai, C. L. L. Iron-catalysed sp3-sp3 cross-coupling reactions of unactivated alkyl halides with alkyl Grignard reagents. Adv. Synth. Catal. 2007, 349, 1015-1018.

[24] Correa, A.; Manche, O. G.; Bolm, C. Iron-catalysed carbon-heteroatom and heteroatom-heteroatom bond forming processes. Chem. Soc. Rev. 2008, 37, 1108-1117.

[25] Limmert, M. E.; Roy, A. H.; Hartwig, J. F. Kumada coupling of aryl and vinyl tosylates under mild conditions. J. Org. Chem. 2005, 70, 9364-9370.

[26] Grignard V. Comptes rendus hebdomadaires des séances de l'Académie des sciences 1900, 130, 1322.

[27] Cahiez, G.; Avedissian, H. Highly stereo- and chemoselective iron-catalyzed alkenylation of organomagnesium compounds. Synthesis 1998, 08, 1199-1205.

[28] Dahadha, A. A. Cobalt, copper, and chromium-catalyzed carbon-carbon coupling reactions using a broad spectrum of Grignard reagents as reaction partners. Arkivoc 2019, (i), 106-138.

[29] Martin, R.; Buchwald, S. L. Palladium-catalyzed Suzuki-Miyaura cross-coupling reactions employing dialkylbiaryl phosphine ligands. Acc. Chem. Res. 2008, 41, 1461-1473.

[30] Organ, M. G.; Abdelhadi, M.; Avola, S.; Hadei, N.; Nasielski, J.; Brien, C. J.; Valente, C. Biaryls made easy: PEPPSI and the Kumada-Tamao-Corriu reaction. Chem. Eur. J. 2007, 13, 150-157. 
[31] Li, Z.; Fu,Y.; Guo, Q. X.; Liu, L. Theoretical study on monoligated Pd-catalyzed cross-coupling reactions of aryl chlorides and bromides. Organometallics 2008, 27, 4043-4049.

[32] Neumann, S. M.; Kochi, J. K. Synthesis of olefins. Cross-coupling of alkenyl halides and Grignard reagents catalyzed by iron complexes. J. Org. Chem. 1975, 40, 599-606.

[33] Hedstrçm, A.; Izakian, Z.; Vreto, I.; Carl-Johan Wallentin, C. J.; Norrby. P. O. On the radical nature of ironcatalyzed cross-coupling reactions. Chem. Eur. J. 2015, 21, 5946 - 5953.

[34] Fürstner, A.; Martin, R.; Krause, H.; Seidel, G.; Goddard, R.; Lehmann, C. W. Preparation, structure, and reactivity of nonstabilized organoiron compounds. implications for iron-catalyzed cross coupling reactions. J. Am. Chem. Soc. 2008, 130, 8773-8787.

[35] Parchomyk, T.; Koszinowski, K. Iron-catalyzed cross-coupling: mechanistic insight for rational. applications in synthesis. Synthesis 2017, 49, 3269-3280.

[36] Silberstein, A. L.; Ramgren, S. D.; Garg, N. K. Iron-catalyzed alkylations of aryl sulfamates and carbamates. Org. Lett. 2012, 14, 3796-3799.

[37] Wu, Y. T.; Bandera, D.; Maag, R.; Linden, A.; Baldridge, K. K.; Siegel, J. S. Multiethynyl corannulenes: synthesis, structure, and properties. J. Am. Chem. Soc. 2008, 130, 10729-10739.

[38] Mattarella, M.; Siegel, J. S. Sym- $(\mathrm{CH} 2 \mathrm{X}) 5$-corannulenes: molecular pentapods displaying functional group and bioconjugate appendages. Org. Bimol. Chem. 2012, 10, 5799-5802.

[39] Perry, M. C.; Gillett, A. N.; Law, T. C. An unprecedented iron-catalyzed cross-coupling of primary and secondary alkyl Grignard reagents with non-activated aryl chlorides. Tetrahedron Lett. 2012, 53, 4436-4439.

[40] Guo, W. J.; Wang. Z. X. Iron-catalyzed cross-coupling of aryltrimethylammonium triflates and alkyl Grignard reagents. Tetrahedron 2013, 69, 9580-9585.

[41] Agrawal, T.; Cook, S. P. Iron-catalyzed cross-coupling reactions of alkyl grignards with aryl sulfamates and tosylates. Org. Lett. 2013, 15, 96-99.

[42] Dahadha, A. A.; Imhof, W. A comprehensive study of the effects of spectator ligands, transition metals and lithium halide additives on the efficiency of iron, nickel and palladium-catalyzed cross-coupling reactions of cyclohexyl magnesium bromide with fluorinated bromobenzene. Arkivoc 2013, (iv): 200-216.

[43] Rushworth. P. H.; Hulcoop, D. G.; Fox, D. J. Iron/tetramethylethylenediamine-catalyzed ambienttemperature coupling of alkyl Grignard reagents and aryl chlorides. J. Org. Chem. 2013, 78, 9517-9521.

[44] Chen, X.; Quan, Z. J.; Wang, X. Z. Iron-catalyzed cross-coupling of heteroaromatic tosylates with alkyl and aryl Grignard reagents. Appl. Organomet. Chem. 2015, 29, 296-300.

[45] Muñoz, S. B.; Daifuku, S. L.; Sears, J. D.; Baker, T. M.; Carpenter, S. H.; Brennessel, W. W.; Neidig, M. L. The N-Methylpyrrolidone (NMP) effect in iron-catalyzed cross-coupling with simple ferric salts and MeMgBr. Angew. Chem. 2018, 130, 6606-6610.

[46] Agataa, R.; Iwamoto, T.; Nakagawa, N.; Isozaki, K.; Hatakeyama, T.; Takaya, H.; Nakamura, M. Iron fluoride/N-heterocyclic carbene catalyzed cross coupling- between deactivated aryl chlorides and alkyl Grignard reagents with or without $\beta$-hydrogens. Synthesis 2015, 47, 1733-1740.

[47] Tindall, D. J.; Krause, H.; Furstne, A. Iron-catalyzed cross-coupling of 1-alkynylcyclopropyl tosylates and related substrates. Adv. Synth. Catal. 2016, 358, 2398-2403.

[48] Rivera, A. C. P.; Still, R.; Frantz. D. E. Iron-catalyzed stereoselective cross-coupling reactions of stereodefined enol carbamates with Grignard reagents. Angew. Chem. Int. Ed. 2016, 55, 6689-6693.

[49] Bisz, E.; Szostak, M. Cyclic ureas (DMI, DMPU) as efficient, sustainable ligands in iron-catalyzed C(sp2)C(sp3) coupling of aryl chlorides and tosylates. Green. Chem. 2017, 19, 5361-5366.

[50] Piontek, A.; Szostak, M. Iron-catalyzed C(sp2)-C(sp3) cross-coupling of alkyl Grignard reagents with polyaromatic tosylates. Eur. J. Org. Chem. 2017, 7271-7276.

[51] Legarda, P. D.; Yanes, R. S.; López, M. T. Q.; Buñuel, E.; Cárdenas, D. J. Iron-catalyzed coupling of propargyl bromides and alkyl Grignard reagents. Eur. J. Org. Chem. 2018, 4900-4904.

[52] Bisz, E.; Szostak, M. Iron-catalyzed C $\left(\mathrm{sp}^{2}\right)-\mathrm{C}\left(\mathrm{sp}^{3}\right)$ cross-coupling of chlorobenzamides with alkyl Grignard reagents: development of catalyst system, synthetic scope, and application. Adv. Synth. Catal. 2019, 361, 8595.

[53] Bisza, E.; Szostak, M. Iron-catalyzed $\mathrm{C}\left(\mathrm{sp}^{2}\right)-\mathrm{C}\left(\mathrm{sp}^{3}\right)$ cross-coupling of chlorobenzenesulfonamides with alkyl Grignard reagents: entry to alkylated aromatics. J. Org. Chem. 2019, 84, 1640-1646.

[54] Deng, Y.; Wei, X.; Wang, X. J.; Sun, Y.; Noël, T. Iron-catalyzed cross-coupling of alkynyl and styrenyl chlorides with alkyl Grignard reagents in batch and flow. Chem. Eur. J. 2019, 25, 14532-14535.

[55] Bisza, E.; Szostak, M. Iron-catalyzed $\mathrm{C}\left(\mathrm{sp}^{2}\right)-\mathrm{C}\left(\mathrm{sp}^{3}\right)$ cross-coupling of aryl chlorobenzoates with alkyl Grignard reagents. Molecules 2020, 25, 230. 
[56] Operamolla, A.; Omar, O. H; Babudri, F.; Vitulli, M.; Farinola, G. M. Iron-catalyzed cross-coupling reaction of aryl Grignard reagents with bis(2-bromovinyl)benzenes. Lett. Org. Chem. 2009, 6, 573-578.

[57] Yamaguchi, Y.; Hiroaki, A.; Makoto, N.; Hideto, H.; Takashi, I.; Masatoshi, A. Synthesis of iron(III) complex bearing tridentate $\beta$-aminoketonato ligand: application to iron-catalyzed cross-coupling reaction of arylmagnesium bromides with alkyl halides. Chem. Lett. 2011, 40, 983-985.

[58] Takuji, H.; Yu-ichi. F.; Yoshihiro, O.; Takuma, I.; Toru, H.; Shintaro, K.; Kazuki, O.; Hikaru, T.; Masaharu, N. Kumada-Tamao-Corriu coupling of alkyl halides catalyzed by an iron-bisphosphine complex. Chem. Lett. 2011, 40, 1030-1032.

[59] Mo, Z.; Zhang, Q.; Deng, L. Dinuclear iron complex-catalyzed cross-coupling of primary alkyl fluorides with aryl Grignard reagents. Organometallics 2012, 31, 6518-6521.

[60] Kuzmina, O. M.; Steib, A. K.; Flubacher, D.; Knochel, P. Iron-catalyzed cross-coupling of N-heterocyclic chlorides and bromides with arylmagnesium reagents. Org. Lett, 2012, 14, 4818-4821.

[61] Kuzmina, O. M.; Steib, A. K.; Markiewicz, J. T.; Flubacher, D.; Knochel, P. Ligand-accelerated iron- and cobalt-catalyzed cross-coupling reactions between N-heteroaryl halides and aryl magnesium reagents. Angew. Chem. Int. Ed. 2013, 52, 4945-4949.

[62] Kawamura, S.; Nakamura, M. Ligand-controlled iron-catalyzed cross coupling of benzylic chlorides with aryl Grignard reagents. Chem. Lett. 2013, 42, 183-185.

[63] Jin, M.; Adak, L.; Nakamura, M. Iron-Catalyzed Enantioselective Cross-Coupling Reactions of $\alpha$ Chloroesters with Aryl Grignard Reagents. J. Am. Chem. Soc. 2015, 137, 7128-7134.

[64] Bauer, G.; Cheung, C.; Hu, X. Cross-coupling of nonactivated primary and secondary alkyl halides with aryl Grignard reagents catalyzed by chiral iron pincer complexes. Synthesis 2015, 47, 1726-1732.

[65] Qi, L.; Ma, E.; Jia, F.; Li, Z. Iron-catalyzed allylic substitution reactions of allylic ethers with Grignard reagents. Tetrahedron Lett. 2016. 57, 2211-2214.

[66] Buono, F. G.; Zhang, Y.; Tan, Z.; Brusoe, A.; Yang, B. S.; Lorenz, J. C.; Giovannini, R.; Song, J. J.; Yee, N. K.; Senanayake, C. H. Efficient iron-catalyzed Kumada cross-coupling reactions utilizing flow technology under low catalyst loadings. Eur. J. Org. Chem. 2016, 15, 2599-2602.

[67] Wu, W.; Teng, O.; Chua, Y. Y.; Huynh, H. V.; Duong, H. A. Iron-catalyzed cross-coupling reactions of arylmagnesium reagents with aryl chlorides and tosylates: influence of ligand structural parameters and identification of a General N-heterocyclic carbene ligand. Organometallics 2017, 36, 2293-2297.

[68] An, L.; Xiao, Y. L.; Zhang, S.; Zhang, X. Bulky diamine ligand promotes cross-coupling of difluoroalkyl bromides by iron catalysis. Angew. Chem. Int. Ed. 2018, 57, 6921-6925.

[69] Teng, Q.; Wu, W.; Duong, H. A.; Huynh, H. V. Ring-expanded N-heterocyclic carbenes as ligands in ironcatalysed cross-coupling reactions of arylmagnesium reagents and aryl chlorides. Chem. Commun. 2018, 54, $6044-6047$.

[70] Wei, Y. M.; Di Ma, X.; Wang, L.; Duan, X. F. Iron-catalyzed stereospecific arylation of enol tosylates using Grignard reagents. Chem. Commun. 2020, 56, 1101-1104.

[71] Hatakeyama, T.; Okada, Y.; Yoshimoto, Y.; Nakamura, M. Tuning chemoselectivity in iron-catalyzed conogashira-type reactions using a bisphosphine ligand with peripheral steric bulk: selective alkynylation of nonactivated alkyl halides. Angew. Chem. Int. Ed. 2011, 50, 10973 -10976.

[72] Cheung, C. W, Ren, P.; Hu, X. Mild and phosphine-free Iron-catalyzed cross-coupling of nonactivated secondary alkyl halides with alkynyl Grignard reagents. Org. Lett. 2014, 16, 2566-2569.

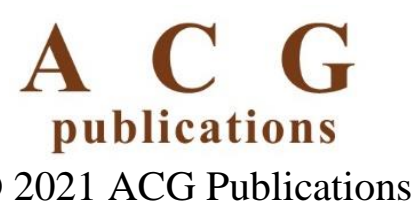

